\title{
Is There a Faction in This List?*
}

\author{
Hilde De Weerdt ${ }^{1} \dagger$ (D), Brent $\mathrm{Ho}^{2}$, Allon Wagner ${ }^{3}$, Qiao Jiyan ${ }^{4}$ and Chu Mingkin ${ }^{5}$ \\ ${ }^{1}$ Leiden University, ${ }^{2}$ Staatsbibliothek zu Berlin, ${ }^{3}$ University of California Berkeley and Tel Aviv University, \\ ${ }^{4}$ Leiden University and ${ }^{5}$ University of Hong Kong \\ †Corresponding author. Email: h.g.d.g.de.weerdt@hum.leidenuniv.nl
}

(Received 27 February 2020; accepted 5 March 2020)

\begin{abstract}
This article has two main objectives. First, we aim to revisit debates about the structure of Song Dynasty faction lists and the relationship between eleventh- and twelfth century factional politics on the basis of a large-scale network analysis of co-occurrence ties reported in the prose collections of those contemporary to the events. Second, we aim to innovate methodologically by developing a series of approaches to compare historical networks of different sizes with regard to overall network metrics as well as the significance of particular attributes such as native and workplace in their makeup. The probabilistic and sampling methods developed here should be applicable for various kinds of historical network analysis. The corresponding data can be found here: https://doi.org/10.17026/dans-xtf-z3au.
\end{abstract}

Keywords: factionalism; political history; Song history; medieval history; historical social network analysis

Chinese historians past and present have written about factionalism as a persistent problem of specifically Chinese court politics. They have traced factionalism back to the Eastern Han Dynasty (25-220) when court officials and eunuchs created lists of enemies and persecuted each other. The factions of the Tang Dynasty (618-907) councilors Niu Sengru 牛僧孺 (778-847) and Li Deyu 李德裕 (787-850) marked a second highpoint in historical genealogies of the phenomenon of factionalism, understood as destructive infighting among powerholders at court. According to such accounts, the Song Dynasty (960-1276) occupied a unique place in the history of Chinese factionalism. ${ }^{1}$

${ }^{*}$ Hilde De Weerdt was the lead author; Brent Ho extracted and prepared all data; Allon Wagner contributed the network and probabilistic analysis; Qiao Jiyan reviewed the literature on factionalism; and Chu Mingkin supervised the data curation. Wang Wenxin, Daniel Stumm, Liu Jialong, Xiong Hueilan, Monica-Klasing Chen, Zhang Xiaofei, and Gabe van Beijeren, all graduate students at Leiden University, helped curate the co-occurrence datasets. The research leading to these results has received funding from the European Research Council under the European Union's Seventh Framework Programme (FP7/2007-2013) / ERC grant agreement $n^{\circ}$ 283525. We thank the two anonymous reviewers for their detailed and constructive feedback; their suggestions have been incorporated throughout the text, so we do not credit them below for individual recommendations.

${ }^{1}$ Luo Jiaxiang 羅家祥, Bei Song dangzheng yanjiu 北宋黨爭研究 (Taibei: Wenjin, 1993), 2; Shen Songqin 沈松勤, Bei Song wenren yu dangzheng-Zhongguo shidafu qunti yanjiu zhi yi 北宋文人與黨

(c) Cambridge University Press 2020. This is an Open Access article, distributed under the terms of the Creative Commons Attribution licence (http://creativecommons.org/licenses/by/4.0/), which permits unrestricted re-use, distribution, and reproduction in any medium, provided the original work is properly cited. 
Wang Fuzhi 王夫之 (1619-1692), for example, held that it was during this period that factionalism had become part of being a literatus. ${ }^{2}$ Modern historians agree that the five-decade long court struggles between "the reformers" supporting Wang Anshi's 王安石 (1021-1086) New Policies and "the conservatives" who opposed them set Song politics on a self-destructive course: factional struggle had become normalized and was a key factor in the series of defeats that the Song state suffered at the hands of their northern and northwestern neighbors in the twelfth and thirteenth centuries. ${ }^{3}$

In this article we will review key questions and assumptions in the debate about the nature and impact of factionalism in the long twelfth century (covering the 1080s through the early 1200s). Were factions a reality or did they exist in name only? Were such realities or fictions the result of intellectual differences, power struggles, or an inevitable outcome of the political system? We attempt to throw new light on these questions by comparing the perceptions of relations among those listed on three published faction lists of the twelfth century. Our approach differs from the extensive scholarship on the key moments of factional struggle in the twelfth century in two ways. First, instead of focusing on particular factions or moments of struggle, we will compare three such moments in order to draw out their particular features and challenge assumptions of a continuous history of the same phenomenon. Second, we adopt a network analytical approach and quantitatively compare the relationships that contemporaries perceived between individuals on the list. In order to trace such perceptions, we have annotated the occurrence of the names of those on faction lists in the remaining collected writings of those who were active around the time when the lists were compiled. We can thus tap into materials that have not been used or only very selectively. Historians of factionalism have mainly relied on Song historical narratives of the events when writing about any of the three twelfth-century faction lists. In recent years, and following a turn towards political communication in Chinese political history, some have also delved into more personal sources, especially letters, to better understand political networking. ${ }^{4}$ On the basis of an examination of the co-occurrence of those on the lists in a broad range of

爭一中國士大夫群體研究之一 (Beijing: Renmin, 1998). There is a mainland edition of Luo's work which includes minor differences; see Luo Jiaxiang, Pengdang zhi zheng yu Bei Song zhengzhi 朋黨之爭 與北宋政治 (Wuhan: Huazhong shifan daxue, 2002). Naitō Torajirō 內藤虎次郎 saw its rootedness in political principles as the distinctive feature of Song factionalism and contrasted it to the predominance of family alliances in Tang factionalism; see Naitō Torajirō, “Gaikakuteki Tō-Sō jidai kan” 概括的唐宋 時代觀, Rekishi to chiri 歷史と地理 9.5 (1922), 1-12.

${ }^{2}$ Wang Fuzhi 王夫之, Song lun 宋論 (Taibei: Liren shuju, 1985), 10.201.

${ }^{3}$ Luo, Bei Song dangzheng yanjiu. For an analysis of the conflict in terms of reformers and conservatives, see James Liu, Reform in Sung China - Wang An-shih (1021-1086) and His New Policies (Cambridge MA: Harvard University Press, 1959), 30-40. Ari Levine, "Che-tsung's Reign (1085-1100) and the Age of Faction" and "The Reigns of Hui-tsung (1100-1126) and Ch'in-tsung (1126-1127) and the Fall of the Northern Sung," in The Cambridge History of China, Volume 5, Part One: Sung China, 960-1279, edited by Denis Twitchett and Paul Jakov Smith, 484-643.

${ }^{4}$ This has resulted in some excellent case studies. Recent monographs include Yu Yingshi 余英時, Zhu Xi de lishi shijie: Songdai shidafu zhengzhi wenhua de yanjiu 朱喜的歷史世界：宋代士大夫政治文化的 研究 (Taibei: Yunchen, 2003); Huang Kuan-chung 黃寬重, Sun Yingshi de xuehuan shenya - daoxue zhuisuizhe dui Nan Song zhongqi zhengju biandong de yinying 孫應時的學宦生涯一道學追隨者對南宋中期 政局變動的因應 (Taibei: Taida chuban zhongxin, 2018); and Xu, Zhou Bida de lishi shijie. See also Liang Jianguo 梁建國, Chaotang zhiwai: Bei Song Dongjing shiren jiaoyou 朝堂之外: 北宋東京士人交遊 (Beijing: Zhongguo shehui kexuechubanshe, 2016); Fang, Jian 方健, Bei Song shiren jiaoyoulu 北宋士人 交遊錄 (Shanghai: Shanghai shudianchubanshe, 2013); and Ming Kin Chu, "Secret of Long Tenure: A Study of Zheng Gangzhong's Letters to Qin Hui's Associates," T'oung Pao 102.1/3 (2016), 121-60. 
sources contemporary to each list's presumed date of compilation, we can show key differences in the manner in which ties between presumed faction members were reported in contemporary sources and investigate their existence and make-up anew.

The lists that we use and, on the basis of the reign periods when they were presumably put together, call "the Yuanyou list," "the Shaoxing list" and "the Qingyuan list"

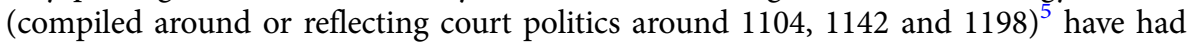
complicated and evolving textual histories. As Luo Changfan has documented in detail, the Yuanyou list had gone through six versions between 1094 and 1133, with the total number of those listed varying from 73 to $541 .^{6}$ The 1104 list with 309 names has become the more widely circulated. This list was officially promulgated; the Shaoxing and Qingyuan lists were more likely privately compiled and, in any case, were not officially issued. ${ }^{7}$ The Qingyuan list as we now have it also reflected changing court politics over the course of a few years. On the occasion of the 1196 departmental examinations the attack on False Learning kicked off in full force. The two supervising examiners accused the leaders of the Learning of the Way of "stealing the power of the sovereign and causing a stir in the empire." In the following years Han Tuozhou's regime grew ever more impatient over the continued influence of "False Learning." One dismissal

\footnotetext{
${ }^{5}$ We based the Yuanyou faction list on Yang Zhongliang 楊仲良, Huang Song tongjian changbian jishi benmo 皇宋通鑒長編紀事本末, in Wanwei biecang 宛委別藏, Vol. 38 (Nanjing: Jiangsu guji, 1988), 122.9b-12b (3804-3810). This list first appeared in a chronological history of the Huizong era compiled by Li Tao 李壽 (1115-1184) in the 1170s and should have been incorporated into his Xu zizhi tongjian changbian 續資治通鑑長編. Even though the parts on Huizong era of the Xu zizhi tongjian changbian are no longer extant, this Yuanyou faction list has been well-preserved, as Yang Zhongliang copied it into his Huang Song tongjian changbian jishi benmo in the thirteenth century. The second list, or the Shaoxing list, is from Shaoxing zheng lun 紹興正論, attributed to a Xiangshan qiaofu 湘山樵夫. This list is quoted in Xu Mengshen 徐夢莘, Sanchao bei meng huibian 三朝北盟會編 (Taibei: Wenhai, 1977), 225.6a-8b and reproduced in Qinding sikuquanshu zongmu tiyao (zhengli ben) 欽定四庫全書總 目 (整理本) (Beijing: Zhonghua, 1997), 61.845-46. The Qingyuan lists are based on Li Xinchuan 李心傳, Jianyan yilai chaoye zaji 建炎以來朝野雜記 (Beijing: Zhonghua, 2000), jiaji 甲集, 6.139-40. Li Xinchuan presented this list of fifty-nine members of the "False faction" in the first installment of his Jianyan yilai chaoye zaji, with a preface dated 1202. The list of thirty-seven officials "attacking False Learning” (gongwei xueren 攻偽學人) was probably also included in Jianyan yilai chaoye zaji, even though it does not appear in all received editions of Jianyan yilai chaoye zaji. It is attributed to this work in Qiaochuan Qiaosou 樵川樵叟, Qingyuan dangjin 慶元黨禁 (Taibei: Shangwu, 1966), 1-5. Both the Yuanyou and Qingyuan lists are included in current editions of the work of the influential Song historian Li Xinchuan. See Li Xinchuan, Dao ming lu 道命錄, in Xuxiu sikuquanshu 續修四庫全庫, Vol. 517 (Shanghai: Shanghai guji, 2002), 2.4b-7a (517-518) and 7b.8a-9a (543-544). For an examination of the bibliographical and textual history of Dao ming lu, see Charles Hartman, "Bibliographic Notes on Sung Historical Works: The Original Record of the Way and Its Destiny (Tao-ming lu) by Li Hsin-ch'uan," Journal of Sung-Yuan Studies 30 (2000), 1-61.

${ }^{6}$ Luo Changfan 羅昌繁, "Yuanyou dangji bei de li hui yu banben yuanliu—jian lun Yuanyou dangji minglu de biangeng” 元祐黨籍碑的立毀與版本源流一兼論元祐黨籍名錄的變更, Beijing shehui kexue, 2018.11, 61-62. Charles Hartman made a similar point about two decades earlier. See Hartman, "The Stele-Register of Partisans from the Era of Primal Bounty," conference paper delivered at the 2000 Association for Asian Studies annual meeting, San Diego, March 10, 2000.

${ }^{7}$ Xu Haoran 許浩然, Zhou Bida de lishi shijie - Nan Song Gao, Xiao, Guang, Ning si chao shiren guanxi zhi yanjiu 周必大的歷史世界一南宋高、孝、光、寧四朝士人關係之研究 (Nanjing: Fenghuang, 2016), 207-11; Li, Chao 李超, “Nan Song Ningzong chao qianqi zhengzhi yanjiu” 南宋寧宗朝前期政治研究 (PhD diss., Zhongshan University, 2017), 50-63. We thank Chen Andi for the latter reference.

${ }^{8}$ Hilde De Weerdt, Competition over Content: Negotiating Standards for the Civil Service Examinations in Imperial China (1127-1279) (Cambridge, MA: Harvard University Asia Center, 2007), 203-4.
} 
succeeded another, and 59 names were reportedly blacklisted by 1202 . The list of 59 men charged with propagating False Learning is, therefore, most likely the result of a series of dismissals that spanned the mid-1190s to the early 1200 s. The goal here is not to trace the textual histories of the individual lists, but rather to attempt a comparison between three lists that captured three moments of presumed factional conflict during the twelfth century. The methodology proposed here could be extended to include variations of the lists (especially the longer Yuanyou list of 541).

Differences in the manner in which ties between presumed faction members were reported in contemporary sources of course reflect the nature of the extant record; but we propose that the differences in the structure of the co-occurrence networks of those on the 1104 and 1198 lists also reflect the changing nature of empire-wide political networking. Some have already suggested that over the course of the Song Dynasty, and in the twelfth century in particular, local and horizontal ties among cultural elites became more clearly pronounced and offered an alternative to the more court-centered politics of the eleventh century and earlier. ${ }^{9}$ We will revisit this hypothesis on the basis of a network analysis of those on the 1198 list whom historians have in recent years considered to be representative of a turn towards localism and horizontal ties, and whom their attackers considered proponents of "False Learning" (weixue 偽學) or the Learning of the Way (Daoxue 道學).

To this end, we will compare the extent to which local affiliation can predict membership in the 1104 and 1198 lists. We will also perform the same network analysis on a sample of contemporaries comparable in size and career status to those on the 1198 list in order to test to what extent the latter group's relationships (as perceived in contemporary prose collections) were representative of the broader cultural elite. Because the methodologies we have adopted are unprecedented in Chinese history ${ }^{10}$ and are broadly applicable to later periods of Chinese (and other) history, we include some observations on our theoretical and methodological assumptions. The accompanying datasets are available on DANS. ${ }^{11}$

We start out with an extensive review of findings on Song factionalism in order to derive from the literature a set of hypotheses to be tested. Our literature review covers more recent and earlier work in order to broadly identify what structures historians have read into these lists and what variables have been used to explain the structures so identified. Following on from the discussion of the literature review and derived hypotheses, we delve into the co-occurrence network analyses of each of the three faction lists and an additional sample network. Because we can now look back on a growing body of scholarship on social and communication networks covering the twelfth century, we also ask how different types of networks reconstructed by modern

\footnotetext{
${ }^{9}$ Robert Hymes, "Sung Society and Social Change," in The Cambridge History of China, Volume 5, Part Two: Sung China, 960-1279, edited by John W. Chaffee and Denis Twitchett (Cambridge: Cambridge University Press, 2015), 636; Ari Levine, Divided by a Common Language: Factional Conflict in Late Northern Song China (Honolulu: University of Hawai'i Press, 2008), 165-66.

${ }^{10}$ In his early inquiry into "the causes, processes, and effects of bureaucratic factionalism," Robert Hartwell made a preliminary attempt to show "how the quantitative data of collective biographical research can, at the least, suggest new lines of inquiry into various aspects of Chinese social and political history." See his "New Approaches to the Study of Bureaucratic Factionalism in Sung China: A Hypothesis," Bulletin of Sung and Yüan Studies 18 (1986), 33, 40. Hartwell then also expressed the hope that "in the future cooperative effort will lead to a more widespread use of these techniques."

${ }^{11}$ For the raw and network data, see Hilde De Weerdt, Brent Ho, Allon Wagner, "Text Mining Twelfth-century Perceptions of Factions Dataset,” DANS (2020) https://doi.org/10.17026/dans-xtf-z3au.
} 
historians relate to each other and whether or not they can be integrated into a coherent theory or set of hypotheses. We will conclude with some historical observations as well as some methodological ones, reflecting on both the affordances and the inadequacies of the kind of large-scale quantitative analysis attempted here.

The present study relies on a statistical analysis of network properties. While social network analysis (SNA) has already been presented and acknowledged in archive-based historical disciplines, ${ }^{12}$ the type of statistical analysis we present has not been common. We therefore present a rigorous mathematical analysis in the main text, and we provide a broader and more intuitive overview in the appendix. We hope it will serve as a useful reference for future studies in digital humanities.

\section{On Factionalism}

Factions (dang 黨 or pengdang 朋黨) historically referred to coalitions of those in power. During the Song Dynasty these terms referred to court coalitions in political rhetoric and political practice. In general, factions were loosely and flexibly organized around particular court actors or the geographic areas with which court actors were associated. They did not share formalized programs and did not have a durable organizational structure, even though in political rhetoric their coherence and scope were often presented in such a way as to turn them into formidable opponents of the court hierarchy and imperial authority. Officials ought to face the emperor as individuals and he theoretically retained final authority in deciding all manner of policy and personnel decisions. Forming an alliance based on shared interests also appeared to many to be linked to the pursuit of self-interest rather than the public good. ${ }^{13}$ The faction registers or faction lists (dangji 黨籍) on which our research is based have to be understood in this context. They were compiled and transmitted in historical texts either to name and take action against those who were accused of illegitimately forming a faction, or to commemorate those who had presumably and unjustly been the victims of such blacklisting. Historians generally take the existence of factions or temporary political partnerships for granted, but many question the authenticity of the faction lists under examination here and their coherence; some even doubt the existence of factional struggle or factionalism (dangzheng 黨爭) in Song political practice.

Most modern historical research on Song factional politics is focused on key historical moments escalating in the production of blacklists. In the last four decades political historians have paid special attention to the Chongning 崇寧 registers of 1102-1104 (in

\footnotetext{
${ }^{12}$ For example, Allon Wagner, Yuval Levavi, Sivan Kedar, et al, "Quantitative Social Network Analysis (SNA) and the Study of Cuneiform Archives: A Test-Case Based on the Murašû Archive," Akkadica 134 (2013), 117-34; Caroline Waerzeggers, "Social Network Analysis of Cuneiform Archives: A New Approach," in Documentary Sources in Ancient Near Eastern and Greco-Roman Economic History: Methodology and Practice, edited by Heather D. Baker and Michael Jursa (Oxford: Oxbow, 2014), 20733; Bastian Still, The Social World of the Babylonian Priest (Leiden: Brill, 2019), 27-63. For a preliminary analysis of literary and political connections among scholar-officials during the Yuanyou period based on data harvested from China Biographical Database, see Shang Wenyi and Huang Wenbin, "Investigating the Relationships between Scholars and Politicians in Ancient China: Taking the Yuanyou Era as an Example," Journal of the Japanese Association for Digital Humanities 3.1 (2018), 33-48.

${ }^{13}$ Levine, Divided by a Common Language, 3; and id., "Public Good and Partisan Gain: Political Languages of Faction in Late Imperial China and Eighteenth-Century England," Journal of World History 23.4 (December 2012), 841-82; Hilde De Weerdt, "Reinventing Chinese Political History," inaugural lecture (Leiden: Leiden University, 2014), https:/openaccess.leidenuniv.nl/handle/1887/29857, 10.
} 
which in the end 309 presumed members of the so-called Yuanyou 元祐 faction were blacklisted-with Yuanyou referring to the reign period covering 1086-1093 and Chongning to the 1102-1106 reign period) and the Qingyuan 慶元 (1195-1201) list of 1198 (which included 59 advocates of "False Learning" and, in some accounts, proponents of "a rebellious faction"). ${ }^{14}$ We will start with an overview of the two bodies of literature on each of these outbursts of factional strife, and then move on to a discussion of questions raised by, first, case studies of individuals included in the lists and, second, broader analyses of factionalism throughout the Song period. ${ }^{15}$ The goal here is not to evaluate the merit of different interpretations, but rather to lay out the range of interpretations of the makeup of the lists. The hypotheses derived from these interpretations will, in the next section, be tested against the network of reported ties in contemporary sources.

The literatures on the Yuanyou and Qingyuan factions have taken different tracks. Historians accounting for the political upheavals of the late Northern Song period have been critically concerned with the question of whether the factions and factional struggles related in the sources were products of the political and historical imagination or whether they captured political practice at court. The monographs by Luo Jiaxiang, Ari Levine, and Fang Chengfeng represent three different ways of dealing with this question of the relationship between name and reality. ${ }^{16}$

Luo argues that the currency of the name was a principal cause for Song factionalism. The currency of the name derived from a contradiction inherent in the imperial political system itself. Luo regards the imperial system that the Song had inherited from the Qin (221-206 BCE) and Han (206 BCE-220 CE) as "an autocratic centralization of power” (zhuanzhi zhuyi zhongyang jiquan 專制主義中央集權). ${ }^{17}$ Such a system cannot, by definition, tolerate political factions, but it is precisely because factional behavior is forbidden and subject to severe punishment that naming others' behavior factionalist could become a powerful political strategy. Luo further addresses the question why this strategy became a pervasive practice at the Song court by pointing to an important change in the eleventh-century distribution of power at the court. Song emperors began to see censors and remonstrators, who were in charge of evaluating policy and personnel, as a check on the power of grand councilors. ${ }^{18}$ Censors and remonstrators took advantage of their investigative powers to launch attacks; at the same time, their rise in power also turned these positions into objects of fierce bureaucratic competition. Both developments, in addition to the domestic and external challenges of state finances and warfare, aggravated factionalism in the late eleventh century. Luo and other Chinese historians tend to see these as unique features of Chinese courts, but the general aversion towards a division of power on one hand, and the preference for a balancing of powers within the central bureaucracy that Luo attributes to the Song imperial system, on the other, are in effect tensions inherent in any dynastic

\footnotetext{
${ }^{14} \mathrm{Li}$ Xinchuan, Jianyan yilai chaoye zaji, jiaji, 6.139-40, and Dao ming $l u$, Zhibuzu zhai edition, 7B.5b-6b. Hartman, "The Stele-Register of Partisans from the Era of Primal Bounty"; Levine, Divided by a Common Language, 155-56.

${ }^{15}$ For an overview of political history of the Song Dynasty, see The Cambridge History of China. Volume 5, Part One: The Sung Dynasty and Its Precursors, 907-1279, edited by Denis Twitchett and Paul Jakov Smith (Cambridge: Cambridge University Press, 2009).

${ }^{16}$ Luo, Bei Song dangzheng yanjiu; Levine, Divided by a Common Language; Fang Chengfeng 方誠峰, Bei Song wanqi de zhengzhi tizhi yu zhengzhi wenhua 北宋晚期的政治體制與政治文化 (Beijing: Beijing daxue, 2015).

${ }^{17}$ Luo, Bei Song dangzheng yanjiu, 1.

${ }^{18}$ Luo, Bei Song dangzheng yanjiu, 31.
} 
system. ${ }^{19}$ Dynasts saw themselves confronted with the choice either to insist on unity and ban oppositional forces from their courts, or to balance opposing views at the risk of escalating conflict between court factions.

Luo's emphasis on the currency of the name as a cause of factionalism implies that factional discourse helped create real factions with reformers and anti-reformers attacking and purging each other in turn from the late 1060s through the 1100s, and these larger formations also splitting into sub-factions to engage in further minor conflicts. In Luo's view, this escalating power struggle culminated in an attempt orchestrated by Emperor Huizong 徽宗 (r. 1100-1126) and his reformist councilor Cai Jing 蔡京 (1046-1126) to rid the court once and for all of the anti-reformist coalitions that had come and gone in previous decades. The final 1104 list that we use as the basis for our examination below was preceded by a shorter list with around 120 names in 1102 and an additional list of 98 names one year later. ${ }^{20}$ Luo finds no coherence in the 1104 list. He interprets the presence of some whose presence on the list does not appear to make sense (like former leaders of the New Policies) as evidence that it was the emperor's and councilor's goal to remove any who would pose a challenge regardless of their intellectual or policy agendas. ${ }^{21}$ This kind of factionalism was in Luo's view ultimately responsible for the failure of the New Policies agenda. ${ }^{22}$

Building on Luo's work, Ari Levine argues that name and reality operated according to different logics and should be analyzed separately. He focuses on faction theory and factional rhetoric and shows that these operated according to a set of linguistic rules "that prevented ministers from publicly acknowledging the existence of their own factional affiliations, while they simultaneously accused their adversaries of factionalism."23 The factions of others thereby appeared well-defined and were constructed as legitimate targets of official condemnation and expurgation. Levine acknowledges that factional practice was far murkier and was characterized by fluid partnerships of delimited scope. Even though the blacklists promulgated between 1102 and 1104 presented the listees as members of a single faction, Levine notes that the lists consecutively targeted senior court officials such as councilors, censors, remonstrators, and academicians from past anti-reform regimes, remaining anti-reform officials, and personal enemies of the current councilor, Cai Jing. ${ }^{24}$

Fang Chengfeng takes the critical analysis of Song factional discourse towards its ultimate conclusion. Fang allows for the existence of political groupings but denies that there was such as a thing as factionalism or factional struggle (dangzheng 黨爭) in late Northern Song politics. Even though his work covers a similar time span as Luo's and Levine's, Fang sets out to write a political history that deliberately leaves factionalism out of the picture. Instead he seeks to understand the politics of the late Northern Song court as determined by the interplay between what he calls political structure (the central decision-making organs and players) and political culture (including political theory, ideals, and inclinations). In such a framework political events are no longer explained as the outcome of conflicts that are determined by the social

\footnotetext{
${ }^{19}$ On court factionalism in a comparative context, see Jeroen Duindam, Dynasties: A Global History of Power, 1300-1800 (Cambridge: Cambridge University Press, 2016), chapter. 3, esp. 218-21.

${ }^{20}$ There are different counts for the first list. Some accounts refer to 117 or 119 names, see Luo, "Yuanyou dangji bei de li hui yu banben yuanliu," 60 .

${ }^{21}$ Luo, Bei Song dangzheng yanjiu, 302-6.

${ }^{22}$ Luo, Bei Song dangzheng yanjiu, 315.

${ }^{23}$ Levine, Divided by a Common Language, 17.

${ }^{24}$ Levine, Divided by a Common Language, 155-56.
} 
backgrounds or shared interests of members of factions. Rather, Fang decodes key moments that feature in accounts of factional history as scenes of culture clashes and emotional responses relating to a potential loss of imperial authority. ${ }^{25}$ The Chongning list no longer features in this account as Fang does not regard factional ties as determinants of the political action of scholar-officials at court.

To recapitulate, in all of these accounts, factionalism is seen as a discursive practice that may or may not relate to actual conflicts between political groups. ${ }^{26}$ None, not even Fang, deny the existence of factions. The point that factional ties should not be automatically seen as determinants or explanations of political action is important-there were relatively few flag wavers. However, networking was an increasingly important aspect of Song political culture that did shape political action. The perception of ties between those listed on faction registers can help provide insight into the question whether such lists were mere political weapons or whether they reflected some kind of political network and, if so, what kind. Based on these accounts we can conclude that the 1104 list is likely to be highly clustered: Luo differentiated between seven different faction member types. These types did not cohere into an overall structure, and they covered a broad spectrum of political positions over an extensive period of time. The Yuanyou faction was large, moreover, with over 300 listed names. and it was thus unlikely to form a dense network. Even though one need not agree with Luo's thesis that it was the sole work of Huizong and Cai Jing (who were both credited with writing the base text for the steles on which the registers were engraved), we may assume that the 1104 list was put together by a group with a shared ideological background targeting selected groups with varying political positions. Not even the opposition to the New Policies was a shared political agenda. ${ }^{27}$

\footnotetext{
${ }^{25}$ Fang, Bei Song wanqi de zhengzhi tizhi yu zhengzhi wenhua, 1-5, 59-60, 69-75, 94-101. Fang argues that Empress Dowager Gao invented factions such as "the faction of the speaking officials" (yanshiguan zhi dang 言事官之黨) and “the faction of Han Wei (1087-1098)" (Han Wei zhi dang 韓維之黨) out of an anxiety over her authority as a female regent. Ibid., 73.

${ }^{26}$ This concern with name and reality is also present in the literature on factional infighting within the Yuanyou group itself. Wang Zengyu, Leung Sze-lok, and Fang Chengfeng have all questioned the validity of using the conventional framework of divisions between the Luo 洛, Shu 蜀, and Shuo 朔 factions. See Wang Zengyu 王曾瑜, “Luo, Shu, Shuo dangzheng bian”洛、蜀、朔黨爭辨, in Jin xin ji 盡心集, ed. Wu Rongzeng 吳榮曾 (Beijing: Zhongguo shehui kexue, 1996), 351-69; Leung Sze-lok 梁思樂, “Shuo dang yu Bei Song Yuanyou pengdan zhengzhi xin lun-yi Yuanyou wu nian Yiqian Shuo dang yu Han Zhongyan, Wen Yanbo, Fan Chunren de guanxi wei zhongxin” 朔黨與北宋元祐朋黨政治新論 —以 元祐五年以前朔黨與韓忠彥、文彥博、范純仁的關係為中心, in “10 zhi 13 shiji Zhongguo guojia yu shehui' guoji xueshe yantaohui ji Zhongguo Song shi yanjiuhui di 16 jie nianhui” lunwenji “10至13世紀 中國國家與社會'國際學術研討會暨中國宋史研究會第16屆年會”論文集 (Hangzhou: Hangzhou shifan daxue, 2014), 100-123, and id., "Bei Song pengdang zhengzhi yanjiu moshi de huigu yu zhanwang-yi 'Luo Shu Shuo dangzheng' shuofa wei li” 北宋朋黨政治研究模式的回顧與展望一以“洛蜀朔黨爭”說法為 例, in Yan Song san ji 研宋三集, ed. Choi Sung-hei 蔡崇禧, Chau Chan Wai-yi 鄒陳惠儀 and Leung Sze-lok 梁思樂 (Hong Kong: Hong Kong Yan Song Xuehui, 2016), 47-62; and Fang, Bei Song wanqi de zhengzhi tizhi yu zhengzhi wenhua, 59-81. Others have taken the existence of factional infighting among the conservatives as a given, see Wang Shuizhao 王水照, “Lun Luo Shu dangzheng de xingzhi yu yiyi” 論洛蜀黨爭的性質與意義, Hebei shiyuan xuebao 1995.1, 13-18+42; Shen, Bei Song wenren yu dangzheng, 145-55; Xiao Qingwei 蕭慶偉, Bei Song xin jiu dangzheng yu wenxue 北宋新舊黨爭與文學 (Beijing: Renmin wenxue, 2001), 56-64; and Tu Mei-yun 涂美雲, Bei Song dangzheng yu wen huo, xue jin zhi guanxi yanjiu 北宋黨爭與文禍、學禁之關係研究 (Taibei: Wanjuanlou, 2012), chapter 4.

${ }^{27}$ Hartman, "The Stele-Register of Partisans from the Era of Primal Bounty"; Luo, "Yuanyou dangji bei de li hui yu banben yuanliu."
} 
In contrast with the literature on the Northern Song, historians writing on the 1198 list of followers of False Learning have been far less concerned with the relationship between the name and reality of factional struggle and see it as an expression of a major factional conflict. The debate has mostly revolved around the question whether the list was the result of intellectual differences between those persecuted and their attackers, the product of power struggles and personal vendettas at court, or some combination of intellectual and political factors. We will briefly set out the range of arguments proposed, with an eye to formulating from these arguments hypotheses regarding the form the ties between those on the list might take.

For some the list was the predictable outcome of intellectual tensions caused by the growing influence of Neo-Confucian movements that were commonly referred to as "the Learning of the Way" (Daoxue) by the last decades of the twelfth century. ${ }^{28}$ Those identifying with the Learning of the Way advocated a reorientation of Song society and the polity on the basis of a moral philosophy and practices of self-cultivation that they saw articulated in a new canon of scriptures from Antiquity. Under the informal leadership of skillful organizers like Zhu Xi 朱喜 (1130-1200), their influence had spread in the provinces over the course of the twelfth century through the founding of academies, shrines, community granaries, and other initiatives intended to help realize that vision. Their political influence at court had waxed and waned, but vocal reformers with Learning of the Way sympathies had gained the support of councilors and been recommended for influential court posts in the 1180s and 1190s. Some historians have interpreted the proscription of the Learning of the Way in the mid-1190s and the compilation of the blacklist in 1198 as an attack on Learning of the Way philosophy or a broader anti-intellectual assault on the scholarly community.

Different rationales have been provided for such an interpretation. Some follow in the footsteps of the earliest histories of the ban on the Learning of the Way and point to the long history of the movement's victimization. Learning of the Way intellectual discourse was new and had therefore time and again proven unpalatable to more traditional scholar-officials. ${ }^{29}$ Lin Yisheng builds on Song critiques of the movement and explains that the proscription resulted from the joining of large numbers of opportunistic sycophants who were not really part of the authentic core fellowship. ${ }^{30} \mathrm{Du}$ Wenyu argues that the continued flurry of attacks and the issuing of the list even after earlier attacks had already resulted in the removal of men on it shows that with the blacklist its architects aimed to remove the social basis for the support of the Learning of the Way. Du adds that a careful analysis of the 59 names on the list reveals that ties to the Learning of the Way cannot be ascertained for only eight or nine. ${ }^{31}$

Along with Yu Yingshi many historians have recently proposed that the list can be best interpreted as an effort to contain the Learning of the Way's political influence. Opinion remains divided as to whether the blacklist has to be understood as a reaction

\footnotetext{
${ }^{28}$ For a discussion of the history of the meaning and uses of daoxue or the learning/Learning of the Way, see De Weerdt, Competition over Content, ch 1.

${ }^{29}$ Fan Lizhou 范立舟, Lixue de chansheng jiqi lishi mingyun 理學的產生及其歷史命運 (Xi'an: Shanxi renmin, 2001), 318-19.

${ }^{30}$ Lin Yi-sheng 林益勝, Qingyuan dang'an zhi yanjiu 慶元黨案之研究 (MA thesis, National Taiwan University, 1970); Zhou Mi, Guixin zashi 癸辛雜識 (Beijing: Zhonghua, 1988), 169-70.

${ }^{31}$ Du Wenyu 杜文玉, “Qingyuan dang jin shu lun 慶元黨禁述論, ” Weinan shizhuan xuebao 渭南師專 學報, 1992.4, 30-39.
} 
of the councilor Han Tuozhou 韓佗䡒 (?-1207), “an autocrat lacking education,” against Learning of the Way critiques ${ }^{32}$ or as a concerted effort on the part of scholarofficials opposed to the Learning of the Way. ${ }^{33}$ According to the latter, the ascendancy of the Learning of the Way at court in the 1180s under Councilor Zhou Bida 周必大 (1126-1204), created tensions at court that resulted in a joint attack by a group of 37 officials listed as "those attacking False Learning." The relaxation of the ban in 1202 also suggests, in this reading, that Councilor Han Tuozhou had not been intent on banning the Learning of the Way and that he let the matter drop as soon as the main advocates of the ban had passed away or left the court. Cheng Chih-hua included an analysis of the intellectual, career, and geographical backgrounds of men on both lists. He concluded that for 42 men on the blacklist an intellectual genealogy leading back to the Cheng brothers, the presumed eleventh-century intellectual ancestors of the Learning of the Way, can be established. Intellectual ties were therefore a factor in the formation of the group, and political connections among them further solidified their intellectual fellowship. In contrast to those under attack, the vast majority of officials held responsible for the persecution of False Learning in the 1190s shared political ties but not intellectual genealogies. ${ }^{34}$

The emphasis on the intellectual coherence of the group and the interpretation of the ban as an attack on the Learning of the Way was challenged early on by the late Conrad Schirokauer. Schirokauer compared the lists of attackers and victims and concluded that over half of the victims were intellectuals of some note, but that their number "represented every significant trend in Southern Song thought." 35 The opposite applied to their attackers: none were prominent intellectuals or associated with a prominent school of thought. Geographical background was in his analysis not a variable that could explain the formation of either group. On the whole, Schirokauer concluded that anti-intellectualism broadly defined rather than a particular animosity towards Zhu Xi's Learning of the Way could explain the ban. ${ }^{36}$ Schirokauer added that contemporary accusations of opportunistic sycophancy further implied that "weixue" carried a double meaning, not only a fixed "false doctrine" such as either the Learning of the Way or Yongjia scholarship, but also a "false pretense of scholarship."

In addition to the above scholarship on the presence or absence of intellectual coherence among those banned, there is an equally large body of scholarship that interprets the blacklist as the result of political intrigue and power struggles among court factions. Opinions differ on the question of the nature of the factions involved. Some consider this to have been a struggle between scholar-officials and imperial favorites (with Han Tuozhou who started out within the imperial guard before rising to the post of

\footnotetext{
${ }^{32}$ Azuma Juji 吾妻重二, Zhuzi xue de xin yanjiu - jinshi shidafu sixiang de zhangkai 朱子學的新研 究一近世士大夫思想的展開 (Beijing: Shangwu, 2017), 335.

${ }^{33}$ Gao Jichun 高紀春, “Daoxue yu Nan Song zhongqi zhengzhi-Qingyuan dangjin tanyuan” 道學與南 宋中期政治一慶元黨禁探源 (PhD diss., Hebei University, 2001), esp. 76.

${ }^{34}$ Cheng Chih-hua 程誌華, “Xueshu yu zhengzhi: Nan Song 'Qingyuan dangjin’ zhi yanjiu” 學術與政 治：南宋“慶元黨禁”之研究 (MA thesis, National Tsing Hua University, 1996), 110-13, 120-22, 125.

${ }^{35}$ Conrad Schirokauer, "The Political Thought and Behavior of Chu Hsi" (PhD diss., Stanford University, 1960), 150. See also id., "Neo-Confucians Under Attack: The Condemnation of Wei-hsueh," in Crisis and Prosperity in Sung China, edited by John Winthrop Haeger (Tucson: The University of Arizona Press, 1975), 186.

${ }^{36}$ Schirokauer, "The Political Thought and Behavior of Chu Hsi," 153.

${ }^{37}$ Schirokauer, "The Political Thought and Behavior of Chu Hsi," 150; cf. id., "Neo-Confucians Under Attack," 195.
} 
councilor), ${ }^{38}$ others deny the importance of Han Tuozhou in factional struggle and see this as the result of infighting among different cliques of scholar-officials. ${ }^{39} \mathrm{Li}$ Jiaju and $\mathrm{Yu}$ Yunguo contend that over one third of the men on the list had no connection to the Learning of the Way and no shared policy agenda; the only commonality among those on the blacklist is that they had all at one point directly or indirectly offended Han Tuozhou by offering critique or supporting the critique of others. ${ }^{40}$ The list was an act of retaliation against those who had not supported Han Tuozhou and an attempt to prevent their future comeback-in his detailed account of the political events at the courts of emperors Guangzong 光宗 (r. 1190-1194) and Ningzong 寧宗 (r. 1195-1224), Yu Yunguo also explains that this list, like the 1104 list, should be seen as one step in a gradual process. Some names on the 1198 list, which we only have in historical accounts written after the event, were added in the following two years. The last one on the list, for example, was a commoner, Lü Zutai 呂祖泰, who had beaten the drum at the Drum Tower in the capital and petitioned to have Han Tuozhou executed in $1200 .{ }^{41} \mathrm{Li}$ Chao reconciled these two angles by proposing that Han Tuozhou and Emperor Ningzong had at first led the attack on a group of reformminded officials led by Councilor Zhao Ruyu 趙汝愚 (1140-96), but that the conflict changed when Han and some officials shifted towards a more conciliatory position. Han's conciliatory moves provoked further retaliation by those opposed to Zhao's faction, so that the list was amplified in 1199 and the early 1200s. Li argues persuasively that Zhao Ruyu and other councilors shared with the others on the list an interest in reform, even though the intellectual commitments may have varied somewhat in focus, strength, and exclusivity. ${ }^{42}$

There are finally some further variations on this argument that allow for a combination of intellectual and political connections. Like Yu Yingshi, Chang Weiling sees the political conflict as one between imperial favorites and officials with a clearly pronounced interest in the Learning of the Way. ${ }^{43}$ Others, like He Jun, have addressed the question from the perspective of intellectual history and argue that the politics of factionalism did not prevent the continuation of intellectual activity. The fortunes of the schools of thought involved in these political conflicts only changed following further political changes in the thirteenth century. ${ }^{44}$

There is an extensive and growing body of literature on both the major and the minor intellectual and political figures in the Qingyuan blacklist, including dedicated

\footnotetext{
${ }^{38}$ Li Jiaju 麗家駒, “Shilun guanyu Han Tuozhou pingjia de jige wenti” 試論关於韓侘贵評價的几个問 題, Zhongguoshi yanjiu, 1981.2, 151; Yu Yunguo 虞雲國, Song Guangzong. Song Ningzong 宋光宗. 宋寧宗 (Changchun: Jilin wenshi, 2004), 176-77.

${ }^{39}$ Huang Chun-yen 黃俊彥, “Han Tuozhou yu Nan Song zhongqi de zhengju biandong” 韓捤胄與南宋 中期的政局變動 (MA thesis., National Taiwan Normal University, 1976), 140-41. We thank Chu Ping-tzu for supplying this reference.

${ }^{40} \mathrm{Li}$ Jiaju 麗家駒, “Shilun guanyu Han Tuozhou pingjia de jige wenti” 試論关於韓侘冒評價的几个問 題, Zhonguoshi yanjiu, 1981.2, 148; Yu Yunguo 虞雲國, Song Guangzong. Song Ningzong 宋光宗.宋寧宗 (Changchun: Jilin wenshi, 2004), 163.

${ }^{41}$ Yu, Song Guangzong. Song Ningzong, 163n1.

${ }^{42} \mathrm{Li}$, "Nan Song Ningzong chao qianqi zhengzhi yanjiu," chapters 1 and 3.

${ }^{43}$ Chang Weiling 張維玲, Cong Nan Song zhongqi fan jinxi zhengzheng kan daoxue xing shidafu dui “huifu” taidu de zhuanbian (1163-1207) 從南宋中期反近習政爭看道學型士大夫對“恢復”態度的轉變 (1163-1207) (Taibei: Huamulan, 2010).

${ }^{44}$ He Jun 何俊, “Qingyuan dangjin de xingzhi yu wan Song ruxue de paixi zhenghe” 慶元黨禁的性質與 晚宋儒學的派系整合, Zhongguo shi yanjiu 中国史研究 2004.1, 109-17.
} 
monographs on major figures like Zhu $\mathrm{Xi}$ and $\mathrm{Zhou} \mathrm{Bida,}{ }^{45}$ and some minor figures as well. ${ }^{46}$ Some scholars also shed light on factionalism through the experiences of those who were not on the Qingyuan list but who lived under its shadow and sought to readjust their personal network. ${ }^{47}$ Biographical studies and articles covering the relationships of individuals and their involvement in the factional struggles of the late twelfth century tend to highlight particular relations between small numbers of individuals within the group, and give more weight to ties based on locality, marriage, and friendship. Even though the difference in scale produces additional evidence of different types of connections among faction members, in general these studies present interpretations of Qingyuan factionalism and the 1198 blacklist that fall within the types of explanation already introduced above. Just as opinions on the list's overall organization range from political to intellectual explanations, individual studies on, for example, Zhou Bida, one of the four former councilors on the list, either present him as an accidental casualty of a political conflict between two camps without strong intellectual interests, ${ }^{48}$ or argue that he was the political leader of the Learning of the Way and maintained close ties with Yongjia intellectuals in particular. ${ }^{49}$

Based on the above scholarship we can hypothesize two scenarios regarding the network of co-occurrence ties among those on the Qingyuan list. Regardless of whether we privilege an intellectual or political explanation, the nature of the network ought to be either dense or clustered in a number of clearly distinguishable subgroups. If one considers the group of 59 to be either a highly integrated intellectual community of associates of the Learning of the Way, or a group of political reformers taking collective action against common enemies, then the network of perceived ties is likely to be dense, with many nodes sharing ties with each other. If, on the other hand, one holds the view that the majority had no connection to the Learning of the Way and rather consisted of different schools of thought, or only took part in occasional and small-scale joint actions such as policy critiques or personnel recommendations, then the network of perceived ties is likely to break down in separate clusters with no or with only limited ties between members of different clusters. Several of the authors compiled tables of geographical origin, family background (in terms of prior experience in office-holding), career relations, and year of examination success, but concluded that none of these variables could explain the organization of the group as a

\footnotetext{
${ }^{45}$ See, for example, Yu, Zhu Xi de lishi shijie; and Xu, Zhou Bida de lishi shijie. Although Xu invokes Yu's work in the title, he provides an alternative interpretation of Zhou Bida's relationship with the Learning of the Way.

${ }^{46}$ See, for example, Liu Kunxin 劉坤新, “Peng Guinian yanjiu” 彭龜年研究 (MA thesis, Heibei daxue, 2011); Zhang Shugong 張書功, “Yang Jian shengping yu shehui gaige sixiang yanjiu” 楊簡生平與社會改 革思想研究 (MA thesis, Ningbo daxue, 2013); Qing Yan 卿彦, “Song ren Liu Guangzu xingnian kao” 宋 人劉光祖行年考, in Xin guoxue 新國學 10, edited by Zhou Yukai 周裕鍇 (Chengdu: Sichuan daxue, 2014), 186-213; Wang Youqi 王有琦, “Weizheng yu zhixue-Liu Guangzu sixiang tanyan”為政與治 學—劉光祖思想探研 (MA thesis, Sichuan shifan daxue, 2015); Wang Xiaojuan 王曉鵑, “Wang Houzhi shengping zhushu kao” 王厚之生平著述考, in Gudian wenxian yanjiu 古典文獻研究17, edited by Cheng Zhangcan 程章燦 (Nanjing: Fenghuang, 2015), 269-83; and Wang Xiaoping 王小平, “Cai Youxue yanjiu” 蔡幼學研究 (MA thesis, Sichuan daxue, 2017).

${ }^{47}$ See, for example, Huang, Sun Yingshi de xue huan shengya. As Sun had friends on the list, this book also includes case studies of some blacklisted figures, including Lü Zujian and Xiang Anshi 項安世 (11291208) (ibid., chapter 6).

${ }^{48} \mathrm{Xu}$, Zhou Bida de lishi shijie, chapter 3, esp. 211, 222.

${ }^{49} \mathrm{Li}$ Chao 李超, “Zhou Bida, Zhao Ruyu, yu Yongjia shiren” 周必大、趙汝愚與永嘉士人, Wenzhou daxue xuebao 温州大学学报, 30.5 (2017), 75-81.
} 
whole. ${ }^{50}$ Authors of case studies, on the other hand, tend to give more weight to native place and marriage in explaining connections among small groups of members. ${ }^{51}$ Both of these types of findings would imply that the second scenario is more likely. This scenario is also more likely if one takes the view that an accumulation of small-scale personal conflicts resulted in the compilation of the list.

The third group that we will be examining here, those banned under Councilor Qin Gui 秦檜 (1090-1155) in the 1140s, has received less scholarly attention. Those who have written about the factionalism of the early Southern Song court and the ban on “confined learning" (zhuanmen zhi xue 專門之學) employ similar frameworks as those writing about the later ban on False Learning and mainly debate the role of intellectual and political factors. Gao Jichun argues that intellectual factors shaped the formation of political associations at Gaozong's 高宗 (r. 1127-1162) court, and political and institutional factors ultimately sealed the fate of the pro-peace faction centered on Councilor Zhao Ding 趙鼎 (1084-1147). Diverging opinions on the merits of “reformist" thinking (as embodied in Wang Anshi's vision of learning and governance) and "antireformist” thinking (as embodied in Cheng Yi's 程頣 (1033-1107) vision of learning and governance) shaped politics; Councilor Zhao Ding was considered to favor the latter over the former and to recruit on this basis. The divisive debate about whether or not to settle for peace with the Jurchens hardened the boundaries that divided Zhao Ding's network from their opponents. In Gao Jichun's view the imperial role was a key factor in factionalism: Emperor Gaozong's change of heart about the merits of Neo-Confucian learning sealed the fate of Zhao Ding's network. ${ }^{52}$ In his influential work on early Southern Song political history, Teraji Jun portrayed Zhao Ding's network as a loose alliance of northern emigrés to the south, southern literati, and intellectual types whose only common ground was opposition to the New Policies. ${ }^{53}$ The scholarship thus varies in the significance attached to shared intellectual interests, but on the whole suggests that the network of perceived ties among those banned ought to be clustered with some sharing political ties, others intellectual, and still others regional affiliations.

Besides research on each of the two major moments of factional struggle and the two main faction lists of the twelfth century, there is a small body of historical and political theoretical research linking and comparing factionalism in the Song Dynasty and beyond. ${ }^{54}$ Four different approaches can be broadly distinguished in the literature.

\footnotetext{
${ }^{50}$ Huang, "Han Tuozhou yu Nan Song zhongqi de zhengju biandong," 123-28, 141-44; Cheng, "Xueshuyu zhengzhi," 100-108, 114-18.

${ }^{51} \mathrm{Li}$, "Zhou Bida, Zhao Ruyu, and Yongjia shiren," 75-81.

${ }^{52}$ Gao Jichun 高紀春, “Zhao Ding jituan de wajie yu Luo xue zhi jin” 赵鼎集团的瓦解与洛学之禁, Zhongguo shi yanjiu 1997.3, 108-17.

${ }^{53}$ Teraji Jun 寺地遵, trans. Liu Ching-chen 劉靜貞 and Li Chin-yun 李今蕓, Nan Song chuqi zhengzhishi yanjiu 南宋初期政治史研究 (Shanghai: Fudan daxue, 2016). (This is a Chinese translation of Teraji Jun, Nansō shoki seijishi kenkyū 南宋初期政治史研究 (Hiroshima: Kaisuisha, 1988). Wang Zengyu writes about censorship under Qin Gui but similarly does not perceive this as an organized attack on Neo-Confucian learning. Wang Zengyu 王曾瑜, Song Gaozong 宋高宗 (Changchun: Jilin wenshi, 2004), 210-21. On confined learning in the context of the civil service examinations, see De Weerdt, Competition over Content, 186-87.

${ }^{54}$ In addition to work already mentioned, see Zhu Ziyan 朱子彥 and Chen Shengmin 陳生民, Pengdang zhengzhi yanjiu 朋黨政治研究 (Shanghai: Huadong shifan daxue, 1992), and Liu Xuebin 劉學斌, Bei Song xin jiu dangzheng yu shiren zhengzhi xintai yanjiu 北宋新舊黨爭與士人政治心態研究 (Baoding: Hebei daxue, 2009). For a discussion of earlier work, see Leung, "Bei Song pengdang zhengzhi yanjiu moshi de huigu yu zhanwang-yi 'Luo Shu Shuo dangzheng' shuofa wei li."
} 
First, several authors working on either the Yuanyou and Qingyuan factions observe continuity in the politics of the early and the late twelfth century. Luo Jiaxiang, for example, argues that by blaming the New Policies and the reformers for the defeat against the Jurchens and taking sides retrospectively with those blacklisted, Emperor Gaozong and his court continued the factional rhetoric that had produced the escalation of factional conflict in the late eleventh century. Under such circumstances emperors, court attendants, and officials in the twelfth century were behaviorally inclined to polarize conflict and make personnel decisions along factional lines. ${ }^{55}$ Second, some point to broader cultural continuities and see factionalism as an inevitable outcome of "traditional culture." 56 Third, in more recent work the historiographical parallels between the ways in which the Yuanyou and Qingyuan lists have been recorded in Song historical narratives have come under scrutiny. As briefly explained above, the lists as we have them are not original and singular; they are included in later reproductions and later histories and represented two moments in a developing production of such lists. Historians working on the 1198 list have pointed out that some on the list were ousted in the years that followed and that the list as we now have it may thus date back to a slightly later list produced around 1201 or $1202 .{ }^{57}$ Moreover, the list appears to have been structured in ways reminiscent of the earlier Yuanyou list and was consciously modeled on it. Twelfth-century historians like Li Xinchuan 李心傳 (1166-1243) tended to embed the lists within a history of the victimization of the Learning of the Way and their work thus ought to be read very critically. The third list that we will discuss here, the list of those who were ousted under Qin Gui, should be read with similar care for the same reason.

Continuity tends to be the overarching theme in this literature, but some have underscored significant differences between the earlier and later outburst of factionalism during the Song Dynasty. Robert Hartwell considered factionalism in the Song Dynasty a necessary outcome of leadership transitions within the bureaucracy. He proposed, without substantiating this on the basis of an analysis of faction lists, that the brutalization of factional conflict in the late eleventh and early twelfth century led to a reorientation of family strategies. The purges affected lineage members and led to a decline in the transgenerational survival of elite bureaucratic families, so that by the late twelfth century elite lineages turned away from intermarriages with capital-based bureaucratic families and invested more in local alliances as evidenced in a higher rate of local marriages. ${ }^{58}$ Building on the latest social historical work of Robert Hymes, Ari Levine has argued that in contrast to Northern Song factional rhetoricians who employed a court-centered discourse of political authority, the Learning of the Way advocates banned in the mid-1190s employed a shi-oriented (or gentlemen-oriented) discourse of authority and operated in horizontal networks of likeminded men "below and outside of central government authority." ${ }^{\text {}}$ In this reading Learning of the Way advocates developed a

\footnotetext{
${ }^{55}$ Luo, Bei Song dangzheng yanjiu, 338-45.

${ }^{56}$ Shen Songqin 沈松勤, “Lun Nan Song xiang dang” 論南宋相黨, Zhongguo wenhua yanjiu 中国文化 研究, 2002.2, 70. Shen also embedded this perspective in his two monographs on Northern and Southern Song factionalism; see Shen, Bei Song wenren yu dangzheng and Nan Song wenren yu dangzheng 南宋文人 與黨爭 (Beijing: Renmin, 2005). Zhang Xingwu 張興武 similarly refers to "self-destructive cultural elements” to explain the Qingyuan blacklist. See Zhang, Liang Song Wangzu yu wenxue 兩宋望族與文學 (Beijing: Renmin wenxue, 2010), 233.

${ }^{57} \mathrm{Li}$, "Nan Song Ningzong chao qianqi zhengzhi yanjiu," 50-63; Xu, Zhou Bida de lishi shijie, 207-11.

${ }^{58}$ Hartwell, "New Approaches to the Study of Bureaucratic Factionalism in Sung China: A Hypothesis."

${ }^{59}$ Levine, Divided by a Common Language, 165-66.
} 
more positive understanding of the Chinese term for faction (dang) and used it in reference to themselves. Modern historians have further shown that by the late twelfth century Learning of the Way advocates had developed a clearly distinct and selfidentified association and were seen by their contemporaries to have done this. ${ }^{60}$ For Levine this shift fits into the broader shift identified earlier by Hymes and others from court-centered bureaucratic office-holding to an investment in local welfare projects. Such projects were undertaken in "locally based and horizontally organized" networks. $^{61}$

Levine's observations about the vertical and horizontal organization of Yuanyou versus Qingyuan factional rhetoric and factional networks can be extended into a hypothesis about the nature of the networks of perceived ties between them: the Yuanyou network is likely to be a clustered network with a distinct hierarchy, and the Qingyuan network a dense and close-knit network. Levine dates the localization of Learning of the Way political networks to the thirteenth century, after the Qingyuan ban. Nevertheless, we may also ask whether localization can be observed in the network of perceived ties among Qingyuan faction members.

To summarize, this review has shown that the extensive scholarship on twelfthcentury faction lists and factionalism has so far not yielded a comparison of the groups involved. Researchers who have linked the three major moments of factional struggle in the eleventh and twelfth centuries have favored continuities in intellectual and political culture, political organization, and historiographical frameworks, but have not considered shifts or continuities in the structure of the networks of those on the blacklist. We therefore attempt to make a start here by comparing how ties between those on the list were reported in prose texts written by contemporaries. We will test the main hypotheses that can be derived from the secondary literature on each of the faction lists: 1) the Yuanyou group formed a clustered network made up of different intellectual and political groupings; 2) the Zhao Ding group formed a loose alliance consisting of those linked through an interest in Cheng Yi's vision on moral and social reform, through personal political ties to the councilor, or regional background; 3) the Qingyuan group formed most likely a dense network of those associated with the Learning of the Way or those supporting a Neo-Confucian reform agenda, but, if we follow earlier assessments of listees' connections to the Learning of the Way, a clustered network consisting of separate subgroups with no or with only limited ties between members of different clusters. In terms of long-term trends in cultural elite networks the scholarship suggests that we are likely to see a trend from clustered court-centered networks to dense localized networks.

\section{Statistical Comparison of Network Metrics}

To test these hypotheses, we construct networks for the studied factions and quantitatively analyze their properties. The networks we have constructed consist of the perceived ties reported in the collections of prose writings of those contemporary to the listees, including the collections of the listees. We constructed the datasets in such a fashion that we can differentiate between networks including all ties, networks

\footnotetext{
${ }^{60}$ Peter Bol, Neo-Confucianism in History (Cambridge, MA: Harvard University Asia Center, 2008); De Weerdt, Competition over Content, chapter 1; and Hoyt Tillman, Confucian Discourse and Chu Hsi's Ascendancy (Honolulu: University of Hawai'i Press, 1992).

${ }^{61}$ Levine, Divided by a Common Language, 171.
} 
excluding self-reported ties (those in which an author on the list mentions himself in relation to someone else on the list), and networks excluding the works of those on the list. In these ways we are testing to what extent contemporaries perceived ties between those on the list. Below we first explain how we obtained the data and then move on to an explanation of methodology and findings. We pay particular attention to statistically sound comparison of the networks of different sizes. Analytical and empirical studies have shown that network properties could be tightly correlated with network size, and consequently a numerical comparison is uninstructive. For example, network density tends to decline as the number of nodes increases, and as a result the network densities of the Yuanyou and Qingyuan cannot be directly compared. We will present a statistical methodology for comparing networks of different sizes.

\section{Constructing the Network Datasets}

There are good reasons for extending the scope of the archive from which to examine the relational makeup of political groupings such as factions. To the extent that previous research has addressed the relational structure of the Yuanyou list, for example, it has focused on self-reported relationships among individuals or subsets of individuals, or select attributes drawn from a broad and often unreferenced range of biographical records. Case studies have produced illuminating detail about the ups and down of interactions amongst several individuals, but they tend to make claims about factionalism from the perspective of a relatively small subset of texts and by reproducing the individual biases inherent in the collections included in the investigation. Even when we expand the range of authors included to all within a blacklist, the network is to a large extent determined by authors with a disproportionately large collection. For example, our preliminary examination of the extant correspondence sent by all those on the 1104 list illustrates that the communication network we can reconstruct from that corpus is dominated by the collections of two individuals, Su Shi 蘇軾 (1037-1101) and Huang Tingjian 黃庭堅 (1045-1105). Because we have letters sent by only one sixth of the total number of listees (49 in our count), we can say little about the overall relationships between all in the group. This problem persists even when we include those on the list who can be identified as recipients-the network then still includes only one third of the 309 names (91 in our count). Even though we realize that the broader archive of contemporary prose that we employ is equally shaped by biases of survival and editorial decision-making, we aim to broadly include in our analysis the perceptions of those who were not directly implicated. ${ }^{62}$

\footnotetext{
${ }^{62} \mathrm{We}$ constructed a correspondence network on the basis of comprehensive examination of the letters included in Quan Song wen sent and received by any of the 309 listees. We found 4791 letters sent by 49 persons. For 2595 of those letters we identified the recipients. The identification was based on the by then still incomplete list of letter recipients that was being compiled for the China Biographical Database project (1853). (Peter Bol, Robert Hartwell, Michael Fuller et al., "China Biographical Database Project." (2004) https://projects.iq.harvard.edu/cbdb/home [hereafter CBDB]) The other 742 recipients we were able to identify by using the MARKUS text analysis platform and the allied CBDB Lookup tool which Brent Ho designed in the course of this research and which allows researchers to filter biographical information in CBDB by using criteria such as official title, part of a name, location, and a time span. (Brent Ho and Hilde De Weerdt, "MARKUS: A Markup, Reading, and Visualization Platform for Classical Chinese Texts." (2014) http://dh.chinese-empires.eu/markus/; Brent Ho, "CBDB Lookup Tool." (2014) https://dh.chinese-empires.eu/markus/beta/cbdbLookup.html). We have so far identified 586 letters that
} 
The network data we constructed include any instance in which two names on the list co-occurred in a given text. A text represents any individual piece of prose in a collection, such as a biographical text (xingzhuang 行狀, muzhiming 墓誌銘), an inscription ( $j i$ 記), letter ( $s h u$ 書, $q i$ 啟), and so forth. Due to the high number of those on the list and the amount of text involved, we cannot at this stage say anything about the kind of tie an author established between two individuals. The goal is here exclusively to determine whether contemporaries tended to associate these names with each other and whether the names so related tended to cluster in cliques or show a broadly connected faction. We will start with a brief explanation of the methodology we employed and then present our interpretation of the network data.

We first compiled a corpus of all extant texts written by authors who were active at the time when the list was compiled. We used a list of all authors listed in the Quan Song wen 全宋文 (The Complete Prose of the Song Dynasty) collection and its supplement, ${ }^{63}$ added an index year for each author (corresponding to the China Biographical Database index year for persons), and compiled a list of all authors whose index years fell within a thirty-year spans before and after the years 1104 and 1196. In the case of the Yuanyou list, we compiled the digital text of all prose pieces authored by the resulting 2,231 authors into a corpus of 56,969 documents. For the Qingyuan group we created a corpus of 52,593 documents by 2,598 authors, including all prose texts in Quan Song wen authored by those with a CBDB index year falling between 1166 and 1226 .

The second step was to tag mentions of the listees-309 of them in the case of the Yuanyou group and 59 in the case of the Qingyuan group-in the respective corpora. In order to detect as many mentions as possible, ${ }^{64}$ we created a list of names and alternate names of those on the list, using the China Biographical Database (CBDB) as a source. 301 out of 309 listees were included in CBDB; for the Qingyuan group the result was 54 out of 59. Because Li Xinchuan also listed those whom he regarded as associates of Han Tuozhou and thus the opponents of the Qingyuan group; we also tagged their names and alternate names (using the CBDB data for the alternate names of 34 out of a total of 37 names listed).

For the Yuanyou group, the initial results showed 22,528 hits for 271 names on the list in a much smaller corpus of 10,848 documents by 556 authors. The resulting raw dataset consisted of 31,863 co-occurrences-that is, pairs of names of those on the Yuanyou list mentioned together in one given piece of prose in the corpus. A

\footnotetext{
were exchanged between 91 persons on the list. For letters whose titles indicated that they were written in response to an earlier letter sent by the recipient, we included an extra record, resulting in total of 714 records of letters sent between those on the list. This was intended as a pilot. It is clear that the recipients of a large number of letters were not identified; there is no indication, however, that the strong bias in favor of a few collections and a few authors (477 letters involving Su Shi and 121 Huang Tingjian) would be drastically altered-as the potential recipients of these letters are likely to predominantly be persons not registered on the blacklist.

${ }^{63}$ Quan Song wen 全宋文, edited by Zeng Zaozhuang 曾霜莊 and Liu Lin 劉琳 (Shanghai: Shanghai cishuchubanshe, 2006). For a critical review, see Lee Sukhee, “A Bibliographical Note on 'Quan Song Wen," Journal of Song-Yuan Studies 37 (2007), 161-67. We used the electronic version with supplement edited by Li Weiguo 李伟国, Quan Song wen / Quan Song wen bubian shujuku 全宋文/全宋文补编数据库 (Shanghai: Shanghai cishu chubanshe, 2012?).

${ }^{64}$ It is important to note that the list is not exhaustive. Many alternate names are not included in CBDB and other biographical reference tools. It is also impossible at this point to include any mentions that consist of a last name and an official or honorary title-something that is not uncommon in Song prose. Only full names and alternate names are included in the dataset.
} 
preliminary review of the data highlighted many shortcomings in the dataset, such as misidentifications of alternate names (with some alternate names that can also appear in other meanings creating a large number of false hits), and also alerted us to potential biases created by texts, such as a complete list of all names that tended to skew the data. We therefore conducted two rounds of data curation in which all mentions were checked. $^{65}$ The final curated dataset consisted of 9,407 mentions and 22,640 co-occurrence edges (ties) among 215 persons (nodes) on the list. Two early decisions in the construction of a network concern tie directionality and weighting. Here, consider ties as undirected-A co-occurring with B is the same as B co-occurring with A. Edges are unweighted, which implies no importance is assigned to the number of times a tie is documented (as two persons can co-occur in more than one document). We therefore simplified multiple edges, ${ }^{66}$ resulting in a network of 10,897 unique edges between 215 persons in the Yuanyou case. In the case of the two Qingyuan groups, we created a dataset comprising 19,274 mentions in 10,446 unique documents by 977 authors. From the extracted occurrences of the 96 names, we obtained a set of 8,127 co-occurrences between 87 persons. After two rounds of further checks, we obtained a network of 1,526 co-occurrences (387 unique edges) among 49 blacklisted men.

\section{Statistical Comparison of Quantitative Network Properties ${ }^{67}$}

In Table 1 we list overall network metrics of the Yuanyou and Qingyuan groups. In order to examine potential differences between internal and external perceptions, we list in both instances three different sets of figures: 1) all co-occurrence ties extracted from the two corpora (group 1 and group 3 Anti Han Tuozhou); 2) all co-occurrence ties extracted from the two corpora excluding self-reported ties (thus excluding all instances in which one of the co-occurring names coincides with the name of the author of the text in which the tie is reported; ES groups in Table 1); and 3) all co-occurrence ties extracted from the two corpora excluding ties reported by authors who appear on the original Yuanyou and Qingyuan lists (EFA groups in Table 1). In addition, and for reasons that become readily apparent, we differentiate between the complete list of ties for the Yuanyou group (group 1 VAR) and the curated list (group 1) in which we removed all ties reported in one document that included the full list. For the Qingyuan group we

\footnotetext{
${ }^{65}$ Wang Wenxin, Daniel Stumm, Liu Jialong, Xiong Hueilan, Monica-Klasing Chen, Zhang Xiaofei, and Gabe van Beijeren assisted in the first round of data curation. They verified the names/partial names/alternate names in the datasets, creating lists of hits, errors, and problematic cases that required further checking. In the second round of data curation, Chu Ming-kin resolved the uncertain cases and randomly verified the hits and errors of the previous round (around 40 percent of the errors and 60 percent of the hits). He made some minor amendments. For the verification process, we used Chang Bide 昌彼得, Songren zhuanji ziliao suoyin 宋人傳記資料索引 (Taibei: Dingwen shuju, 1974-76); Li Guoling 李國 玲, Songren zhuanji ziliao suoyin bubian 宋人傳記資料索引補編 (Chengdu: Sichuan daxue chubanshe, 1994); Li Zhiliang 李之亮, Songdai jingchaoguan tongkao 宋代京朝官通考 (Chengdu: Ba Shu shushe, 2003) and Songdai lufen zhangguan tongkao 宋代路分長官通考 (Chengdu: Ba Shu shushe, 2003); Wu Hongze 吴洪澤 and Yin Bo 尹波, eds., Songren nianpu congkan 宋人年譜叢刊 (Chengdu: Sichuan daxue chubanshe, 2003).

${ }^{66} \mathrm{~A}$ graph that allows multiple edges between the same two nodes is called a multigraph, whereas a graph that does not allow them is called a simple graph, hence the term "graph simplification."

${ }^{67}$ For the mathematical analysis of networks, see Mark Newman, Networks, 2nd ed. (Oxford: Oxford University Press, 2018); Vito Latora, et al., Complex Networks: Principles, Methods and Applications (Cambridge: Cambridge University Press, 2017); and Shlomo Havlin and Reuven Cohen, Complex Networks: Structure, Robustness and Function (Cambridge: Cambridge University Press, 2010).
} 
Table 1. Overall network metrics of the Yuanyou and Qingyuan groups (ES: Excluding self-reported ties; EFA: Excluding ties reported by faction authors, i.e., authors appearing on either the Yuanyou or Qingyuan lists)

\begin{tabular}{|c|c|c|c|c|c|c|c|c|}
\hline Network & Group & $\begin{array}{c}\# \\
\text { Nodes }\end{array}$ & $\begin{array}{l}\text { \# Edges (no } \\
\text { simplification) }\end{array}$ & $\begin{array}{l}\text { \# Simple } \\
\text { edges }\end{array}$ & Density & Diameter & $\begin{array}{c}\mathrm{GCC} \\
\left({ }^{*}\right)\end{array}$ & $\underset{(* *)}{\operatorname{Mean} \text { LCC }}$ \\
\hline Group 1 VAR & 1st_Yuanyou & 215 & 22,640 & 10,897 & 0.47 & 9 & 0.91 & 0.85 \\
\hline Group 3 & 3rd_Qingyuan & 76 & 1,526 & 702 & 0.25 & 5 & 0.53 & 0.64 \\
\hline Group 1 & 1st_Yuanyou & 146 & 4,144 & 2,156 & 0.20 & 9 & 0.68 & 0.65 \\
\hline Group 1 ES & 1st_Yuanyou & 139 & 2,322 & 1,174 & 0.12 & 11 & 0.46 & 0.53 \\
\hline Group 1 EFA & 1st_Yuanyou & 66 & 1,254 & 586 & 0.27 & 5 & 0.53 & 0.60 \\
\hline Group 3 ES & 3rd_Qingyuan & 75 & 1,171 & 601 & 0.22 & 5 & 0.50 & 0.61 \\
\hline Group 3 EFA & 3rd_Qingyuan & 48 & 735 & 347 & 0.31 & 4 & 0.54 & 0.64 \\
\hline Group 3 - Anti Han Tuozhou & 3rd_Qingyuan & 49 & 1,526 & 387 & 0.33 & 5 & 0.59 & 0.69 \\
\hline Group 3 ES - Anti Han Tuozhou & 3rd_Qingyuan & 49 & 1,171 & 343 & 0.29 & 4 & 0.56 & 0.66 \\
\hline Group 3 EFA - Anti Han Tuozhou & 3rd_Qingyuan & 29 & 735 & 169 & 0.42 & 5 & 0.61 & 0.71 \\
\hline $\begin{array}{l}\text { Group } 3 \text { - Associated with Han } \\
\text { Tuozhou }\end{array}$ & 3rd_Qingyuan & 27 & 1,526 & 60 & 0.17 & 9 & 0.59 & 0.44 \\
\hline $\begin{array}{l}\text { Group } 3 \text { ES - Associated with Han } \\
\text { Tuozhou }\end{array}$ & 3rd_Qingyuan & 26 & 1,171 & 52 & 0.16 & 6 & 0.59 & 0.45 \\
\hline $\begin{array}{l}\text { Group } 3 \text { EFA - Associated with Han } \\
\text { Tuozhou }\end{array}$ & 3rd_Qingyuan & 19 & 735 & 47 & 0.27 & 5 & 0.61 & 0.52 \\
\hline
\end{tabular}

$\left(^{*}\right)$ GCC $=$ Global clustering coefficient

${ }^{* *}$ LCC $=$ Local clustering coefficient, nodes with no edges or exactly one edge assigned an LCC of 0 
(a)

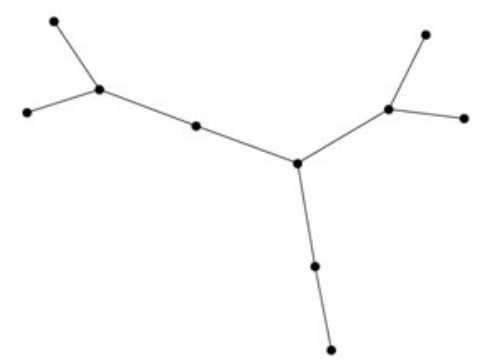

(b)

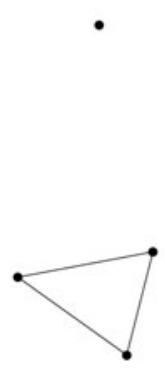

Figure 1. Density vs. Clustering Coefficient

also show the different results for those reportedly blacklisted (here for the sake of convenience labeled Anti Han Tuozhou) and those whom Li Xinchuan listed as the perpetrators of the attack (here labeled Associated with Han Tuozhou).

The metrics used measure the connectedness of the network of perceived ties in different ways. The overall density measures the ratio of actual ties to the potential ties in the network. A density of 1 would mean that all nodes are completely connected to each other; the lower the value the sparser the ties amongst the nodes that are part of the network. The overall density may obscure the extent to which some subgroups in a social network cluster together (i.e., have dense relations amongst each other but not to others in the network-for example, both networks shown in Figure 1 have the same density of 20 percent), so we also measured clustering. We computed the two standard measures for this. The global clustering coefficient (GCC) shows the ratio of realized triads out of the total of potential triads. Triads are triplets of nodes that are connected; like density, the GCC is thus a measure that is applied to the network as a whole. Theoretically, networks in which fewer nodes exercise control over access to information and thus serve in mediator and broker roles, tend to have lower GCCs. By contrast, the local clustering coefficient (LCC) quantifies the embeddedness of individual nodes in clusters by measuring the extent to which neighboring nodes in the network realize the total number of potential ties among them.

However, a direct comparison of quantitative network properties, especially between networks of considerably different sizes, can be misleading due to confounding effects. For example, empirical evidence shows that large social networks tend to have lower densities, possibly due to the inability of one actor to maintain ties to an infinitely large number of peers. ${ }^{68}$ A comparison between a large and a small network that does not take that into account might overestimate the importance of a quantitative density difference, should the larger network have a smaller density, or might underestimate its importance, should the larger network have the higher density. Therefore, we applied formal statistical tests to draw robust conclusions about the similarities and differences between the different networks. We randomly down-sampled the larger network so that its number of nodes equals that of the smaller network, and we repeated the procedure $\mathrm{N}=1,000$ times to compute an empirical p-value (Table 2). Usually, p-values smaller than 0.05 are considered statistically significant. However, when a large number of

\footnotetext{
${ }^{68}$ Marvin D. Krohn, "The Web of Conformity: A Network Approach to the Explanation of Delinquent Behavior," Social Problems 33.6 (1986), Special Theory Issue, S86.
} 


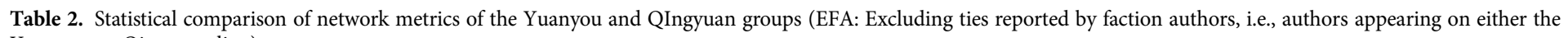
Yuanyou or Qingyuan lists)

\begin{tabular}{|c|c|c|c|c|c|c|}
\hline \multicolumn{3}{|l|}{ Statistical test } & \multicolumn{2}{|c|}{ Statistic value } & \multicolumn{2}{|c|}{ Statistical significance (one-sided emirical $p$-value) } \\
\hline Larger network & Smaller network & $\begin{array}{l}\text { Network property } \\
\text { (statistic) }\end{array}$ & $\begin{array}{l}\text { Null median } \\
\text { value }\left(^{\star}\right)\end{array}$ & $\underset{(* *)}{\text { Observed value }}$ & $\begin{array}{l}\text { Property is higher in } \\
\text { larger network }\end{array}$ & $\begin{array}{l}\text { Property is higher in } \\
\text { smaller network }\end{array}$ \\
\hline Group 1 & Group 3 - Anti Han Tuozhou & Density & 0.20 & 0.33 & 0.004 & 0.997 \\
\hline Group 1 & Group 3 - Anti Han Tuozhou & Diameter & 8.00 & 5.00 & 0.939 & 0.246 \\
\hline Group 1 & Group 3 - Anti Han Tuozhou & GCC & 0.67 & 0.59 & 0.854 & 0.146 \\
\hline Group 1 & Group 3 - Anti Han Tuozhou & mean LCC & 0.53 & 0.69 & 0.004 & 0.996 \\
\hline Group 1 & $\begin{array}{l}\text { Group } 3 \text { - Associated with } \\
\text { Han Tuozhou }\end{array}$ & Density & 0.20 & 0.17 & 0.670 & 0.350 \\
\hline Group 1 & $\begin{array}{c}\text { Group } 3 \text { - Associated with } \\
\text { Han Tuozhou }\end{array}$ & Diameter & 7.00 & 9.00 & 0.287 & 0.765 \\
\hline Group 1 & $\begin{array}{c}\text { Group } 3 \text { - Associated with } \\
\text { Han Tuozhou }\end{array}$ & GCC & 0.65 & 0.59 & 0.709 & 0.291 \\
\hline Group 1 & $\begin{array}{c}\text { Group } 3 \text { - Associated with } \\
\text { Han Tuozhou }\end{array}$ & mean LCC & 0.46 & 0.44 & 0.588 & 0.412 \\
\hline Group 1 & Group 1 EFA & Density & 0.20 & 0.27 & 0.028 & 0.972 \\
\hline Group 1 & Group 1 EFA & Diameter & 8.00 & 5.00 & 0.977 & 0.149 \\
\hline Group 1 & Group 1 EFA & GCC & 0.67 & 0.53 & 0.996 & 0.004 \\
\hline Group 1 & Group 1 EFA & mean LCC & 0.56 & 0.60 & 0.202 & 0.798 \\
\hline $\begin{array}{l}\text { Group } 3 \text { - Anti Han } \\
\text { Tuozhou }\end{array}$ & $\begin{array}{l}\text { Group } 3 \text { EFA - Anti Han } \\
\text { Tuozhou }\end{array}$ & Density & 0.33 & 0.42 & 0.052 & 0.952 \\
\hline $\begin{array}{l}\text { Group } 3 \text { - Anti Han } \\
\text { Tuozhou }\end{array}$ & $\begin{array}{l}\text { Group } 3 \text { EFA - Anti Han } \\
\text { Tuozhou }\end{array}$ & Diameter & 5.00 & 5.00 & 0.852 & 0.639 \\
\hline
\end{tabular}


Table 2. (Continued.)

\begin{tabular}{|c|c|c|c|c|c|c|}
\hline \multicolumn{3}{|l|}{ Statistical test } & \multicolumn{2}{|c|}{ Statistic value } & \multicolumn{2}{|c|}{ Statistical significance (one-sided emirical p-value) } \\
\hline Larger network & Smaller network & $\begin{array}{l}\text { Network property } \\
\text { (statistic) }\end{array}$ & $\begin{array}{l}\text { Null median } \\
\text { value }\left(^{*}\right)\end{array}$ & $\underset{(* *)}{\text { Observed value }}$ & $\begin{array}{l}\text { Property is higher in } \\
\text { larger network }\end{array}$ & $\begin{array}{l}\text { Property is higher in } \\
\text { smaller network }\end{array}$ \\
\hline $\begin{array}{l}\text { Group } 3 \text { - Anti Han } \\
\text { Tuozhou }\end{array}$ & $\begin{array}{l}\text { Group } 3 \text { EFA - Anti Han } \\
\text { Tuozhou }\end{array}$ & GCC & 0.59 & 0.61 & 0.294 & 0.706 \\
\hline $\begin{array}{l}\text { Group } 3 \text { - Anti Han } \\
\text { Tuozhou }\end{array}$ & $\begin{array}{l}\text { Group } 3 \text { EFA - Anti Han } \\
\text { Tuozhou }\end{array}$ & mean LCC & 0.66 & 0.71 & 0.160 & 0.840 \\
\hline $\begin{array}{c}\text { Group } 3 \text { - Associated with } \\
\text { Han Tuozhou }\end{array}$ & $\begin{array}{c}\text { Group } 3 \text { EFA - Associated } \\
\text { with Han Tuozhou }\end{array}$ & density & 0.17 & 0.27 & 0.010 & 0.995 \\
\hline $\begin{array}{c}\text { Group } 3 \text { - Associated with } \\
\text { Han Tuozhou }\end{array}$ & $\begin{array}{c}\text { Group } 3 \text { EFA - Associated } \\
\text { with Han Tuozhou }\end{array}$ & diameter & 7.00 & 5.00 & 0.886 & 0.246 \\
\hline $\begin{array}{l}\text { Group } 3 \text { - Associated with } \\
\text { Han Tuozhou }\end{array}$ & $\begin{array}{c}\text { Group } 3 \text { EFA - Associated } \\
\text { with Han Tuozhou }\end{array}$ & GCC & 0.57 & 0.61 & 0.335 & 0.667 \\
\hline $\begin{array}{l}\text { Group } 3 \text { - Associated with } \\
\text { Han Tuozhou }\end{array}$ & $\begin{array}{c}\text { Group } 3 \text { EFA - Associated } \\
\text { with Han Tuozhou }\end{array}$ & mean LCC & 0.39 & 0.52 & 0.067 & 0.933 \\
\hline $\begin{array}{l}\text { Group } 3 \text { - Anti Han } \\
\text { Tuozhou }\end{array}$ & $\begin{array}{c}\text { Group } 3 \text { - Associated with } \\
\text { Han Tuozhou }\end{array}$ & density & 0.33 & 0.17 & 1.000 & 0.000 \\
\hline $\begin{array}{l}\text { Group } 3 \text { - Anti Han } \\
\text { Tuozhou }\end{array}$ & $\begin{array}{c}\text { Group } 3 \text { - Associated with } \\
\text { Han Tuozhou }\end{array}$ & diameter & 5.00 & 9.00 & 0.113 & 0.899 \\
\hline $\begin{array}{l}\text { Group } 3 \text { - Anti Han } \\
\text { Tuozhou }\end{array}$ & $\begin{array}{c}\text { Group } 3 \text { - Associated with } \\
\text { Han Tuozhou }\end{array}$ & GCC & 0.58 & 0.59 & 0.455 & 0.545 \\
\hline $\begin{array}{l}\text { Group } 3 \text { - Anti Han } \\
\text { Tuozhou }\end{array}$ & $\begin{array}{c}\text { Group } 3 \text { - Associated with } \\
\text { Han Tuozhou }\end{array}$ & mean LCC & 0.65 & 0.44 & 0.996 & 0.004 \\
\hline
\end{tabular}

$\left({ }^{*}\right)$ Median of the network property over $\mathrm{N}=1,000 \mathrm{i}$ down-sampling iterations of larger network (median of empirical null distribution)

$\left({ }^{*}\right)$ Value of the network property in the smaller network 
comparisons is made, the cutoff needs to be adjusted accordingly. In the present case, the Bonferroni significance threshold, the most conservative adjustment, is $0.05 /\left(24^{*} 2\right) \approx$ 0.001. In Table 2, p-values smaller than 0.05 are highlighted in bold font.

Based on the p-values shown in Table 2 we can conclude that the network of perceived ties amongst those blacklisted during the Qingyuan reign (49 out of 59 included in the network) is significantly ${ }^{69}$ denser than both the Yuanyou group (146 out of 309) and those who were listed as their attackers (27 out of 37 ). The conclusion is further supported by observing that the mean local clustering coefficient (LCC) of the blacklisted Qingyuan network is significantly higher than for the other two networks - the LCC measures density of egocentric subnetworks embedded within a given network. On the other hand, the gathered data suggest there is no statistically significant difference in the transitivity of the blacklisted Qingyuan group (its tendency to form triadic closures, which would result in higher global clustering coefficients, GCCs) compared to the other two networks. The global clustering coefficient is similar in all instances. This is particularly noteworthy in the case of the Yuanyou group. Even though the high value is to be expected for the original network which included a document with a long list of faction members that resulted in co-occurrence ties amongst nearly all on the list, the value remains relatively high when this document is removed (Table 1) and for a significantly large group (146 nodes).

From the number of nodes that could be included in each network it is obvious that these findings apply to only a core group within each list; this is especially the case for the larger Yuanyou group (for which a majority of names are not associated with others on the list in the literature analyzed here). Interestingly, in all instances the density amongst the perceived relations increased when we excluded the work of those on the list. This may imply that contemporaries who did not appear on the list conceptualized core groups of actors (consisting of 66, 29, and 19 persons respectively) and viewed the actors within each of these groups as closely associated with each other.

The distribution of the local clustering coefficients (Figure 2) reveals a high disparity among those on the list of the persecuted in the Qingyuan reign (Group 3 Assoc.). This network is characterized by a bimodal division into well- and ill-clustered actors (namely, actors characterized with high and low LCCs, respectively). By contrast, in the Yuanyou group and particularly in the Qingyuan list of presumed attackers (Group 3 Anti), the majority of the actors are well-clustered.

The comparison suggests that the Yuanyou network is both less dense and less locally clustered than the network of those on the Qingyuan blacklist, but, as shown in the comparison of the GCCs, these networks also exhibited similar small world network features. Based on these metrics, the overall trend in cultural elite networks is from a less densely clustered Yuanyou network to a more densely clustered Qingyuan network with greater variation in connectivity among individuals. Zooming into the individual networks, the Yuanyou data suggest that based on the extant prose texts authored by those active around 1102-1104 and gathered in Quan Song wen, about half of those registered on the 1104 blacklist were connected with each other. Contemporaries did not perceive a gathering of smaller cliques without or with few interconnections, intellectual or otherwise. The Yuanyou faction also

\footnotetext{
${ }^{69}$ Significantly refers in this discussion to significance in the statistical sense based on the computed p-values. See the appendix for an overview that does not assume prior mathematical knowledge.
} 


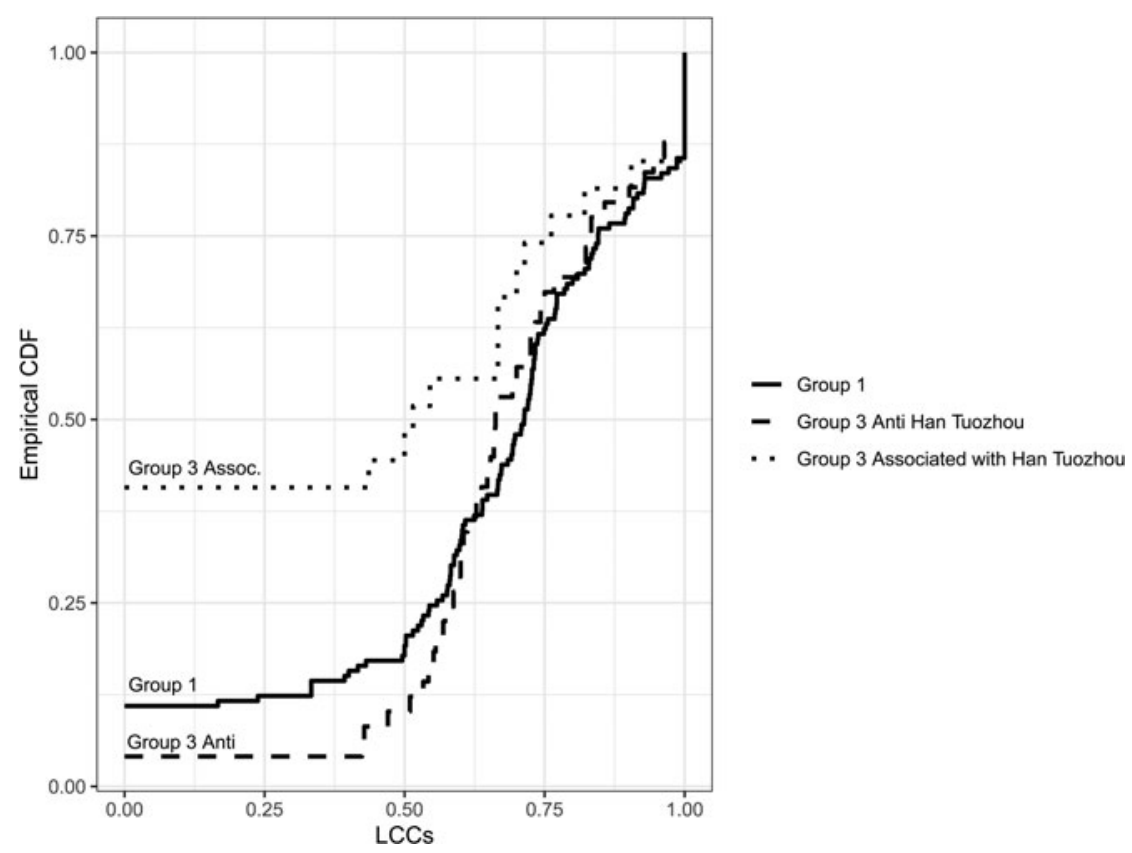

Figure 2. Empirical Cumulative Distribution Function (CDF) of the LCC

emerges here as a large interconnected network of court officials. Whether this result derives from the effect of factional rhetoric that presents factions as united blocks, or whether this reflects the reality of large coalitions overcoming smaller divisions in defiance of the personalities or the policies of those orchestrating the blacklist is difficult to say. The Qingyuan data reviewed thus far do not support the hypothesis of a uniformly dense network, but rather conjure a highly clustered network whose structure could be further explored. As we shall discuss further below, our macroscale observations and data offer a variety of opportunities for further analyses of political association at various scales.

\section{Community Detection and Hierarchy Within Community ${ }^{70}$}

As a first step in this direction we applied various community detection algorithms to the curated datasets, including the Louvain and Leiden modularity algorithms (Figures 4 and 5). ${ }^{71}$ From the results of these community detection methods ${ }^{72}$ we

\footnotetext{
${ }^{70}$ Mark Newman, "Modularity and Community Structure in Networks," Proceedings of the National Academy of Sciences, 103.23 (2006), 8577-82.

${ }^{71}$ On the Louvain algorithm see Vincent Blondel, et al, "Fast Unfolding of Communities in Large Networks," Journal of Statistical Mechanics: Theory and Experiment 10008.10 (2008), 1-12. On the Leiden algorithm see V.A. Traag, L. Waltman, and N.J. van Eck, "From Louvain to Leiden: Guaranteeing Well-Connected Communities," Scientific Reports 9, 5233 (2019), https://doi.org/10.1038/ s41598-019-41695-z

${ }^{72}$ The deposited data include network files with various metrics that can be explored in gephi. Illustrative figures showing both the Leiden modularity analysis and betweenness centrality metrics for individual
} 
can conclude that those featuring on the Qingyuan blacklist tended to be grouped in a handful of similarly-sized small clusters that were connected through nodes with high centrality. The Qingyuan network is thus a hierarchical network. By testing clustering within a network through the differential between the density of ties of a given set of nodes to each other and the sparsity of their ties to other sets of nodes as in the Louvain method, we can be made aware of and perhaps avoid confirmation bias in the interpretation of network data. These tests suggest that contemporaries tended not to report ties between all the different individuals on the list, but that they saw close ties among subgroups who were in part held together through some key figures. Unsurprisingly to historians, Zhu Xi was such a central figure in contemporaries' perceptions and so was Zhao Ruyu, Chen Fuliang 陳傅良 (1137-1203), Ye Shi 葉適 (1150-1223), or Zhou Bida. But there were others as well, like Peng Guinian 彭龜年 (1142-1206), Lou Yue 樓錀 (1137-1213), or Lü Zujian 呂祖儉 (?-1196), who appear central or peripheral in an important way (by forming a robust subgroup), and whose role in intellectual associations and political action may have been relatively underestimated in the scholarship that has been focused on the dominant role of Zhu Xi. ${ }^{73}$ The goal here is not to elaborate further on this, but we want to highlight that the kind of macroscale comparisons of network structure attempted here also have the potential to draw attention to relatively ignored subgroups and intellectual and political brokers overlooked as a result of the later success of the group around Zhu Xi.

The above network analysis of the perceived ties of those on the False Learning list fits best with earlier readings of the list as an amalgam of intellectual formations and/or political partnerships of limited scope, and does not provide support for an overall close-knit intellectual or political organization of Learning of the Way advocates or reform-minded politicians. However, the hierarchy detected in the network has implications for how we understand relationships among clusters and raises questions about the relevance of attributes that have been dismissed as irrelevant in the overall composition of the 1198 group.

\section{Local Connections}

Given the impact of the local turn in recent scholarship in general and in Levine's interpretation of the difference between Yuanyou and Qingyuan factionalism, we tested to what extent shared native place or shared place of official service could explain ties in the Yuanyou and the Qingyuan networks. We extracted CBDB data for the native place and places of service for all groups and constructed networks for the same set of actors as the list co-occurrence networks, but this time with ties denoting shared native place or shared place of service (Figure 3). Toponyms were extracted at a

nodes (using the Chinese names of those blacklisted) are also included so that historians can easily preview clusters and central figures.

${ }^{73}$ The datasets include the centrality of individuals and clusters by various measures. Zhu Xi ranks first by degree centrality, Chen Fuliang sixth, Lü Zujian eighth. The ranking differs in betweenness centrality (measuring the importance of a node in linking the overall network together and not by the overall number of connections) with Zhao Ruyu and Lou Yue outranking the rest by a substantial margin, and Chen Wu 陳 武, Peng Guinian, and Liu Zheng 留正 (1129-1206) also playing a critical role in linking subclusters together. Overall we can conclude that these network analytical results lend support to the increasing attention that has recently been paid to figures like Peng Guinian; they also identify other figures to be looked into. Equally important, they present a larger context within which we can position these figures in relation to each other. 

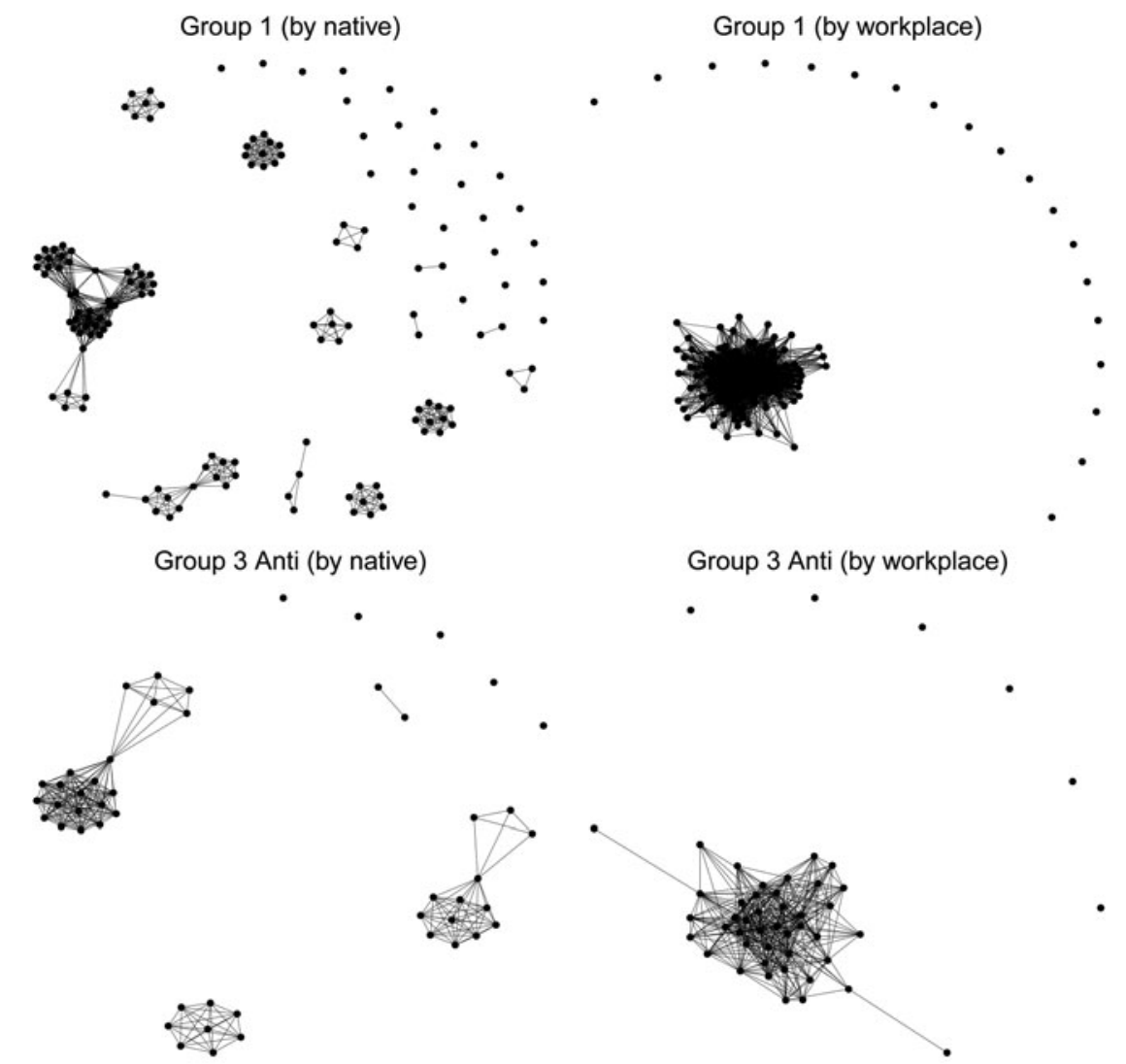

Group 3 Assoc (by native)

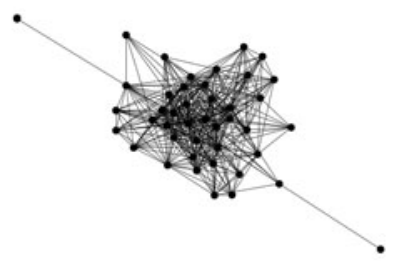

Group 3 Assoc (by workplace)

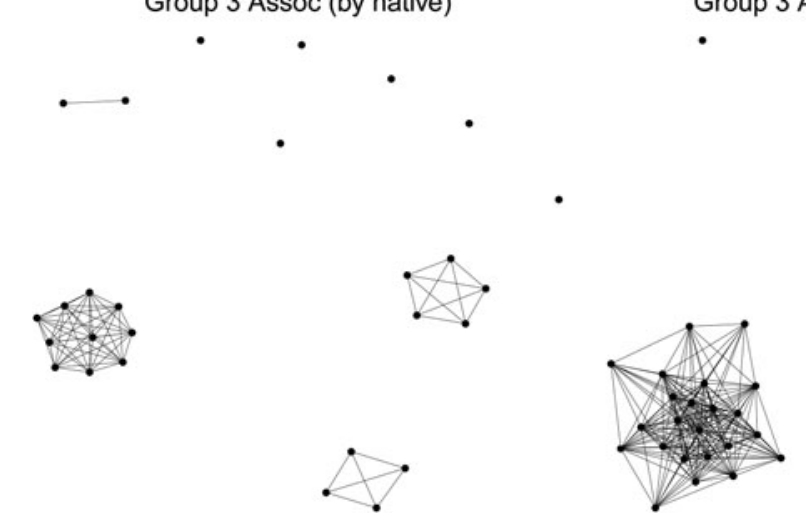

Figure 3. Shared Native Place and Shared Place of Service Toponym Networks

prefecture level, and similar results were obtained when extracting them at a route level (roughly equivalent to later provincial levels). The shared native toponym network in particular exhibited a clear partition into distinct clusters. To quantitatively test the extent to which the shared location networks explain list co-occurrences, we 


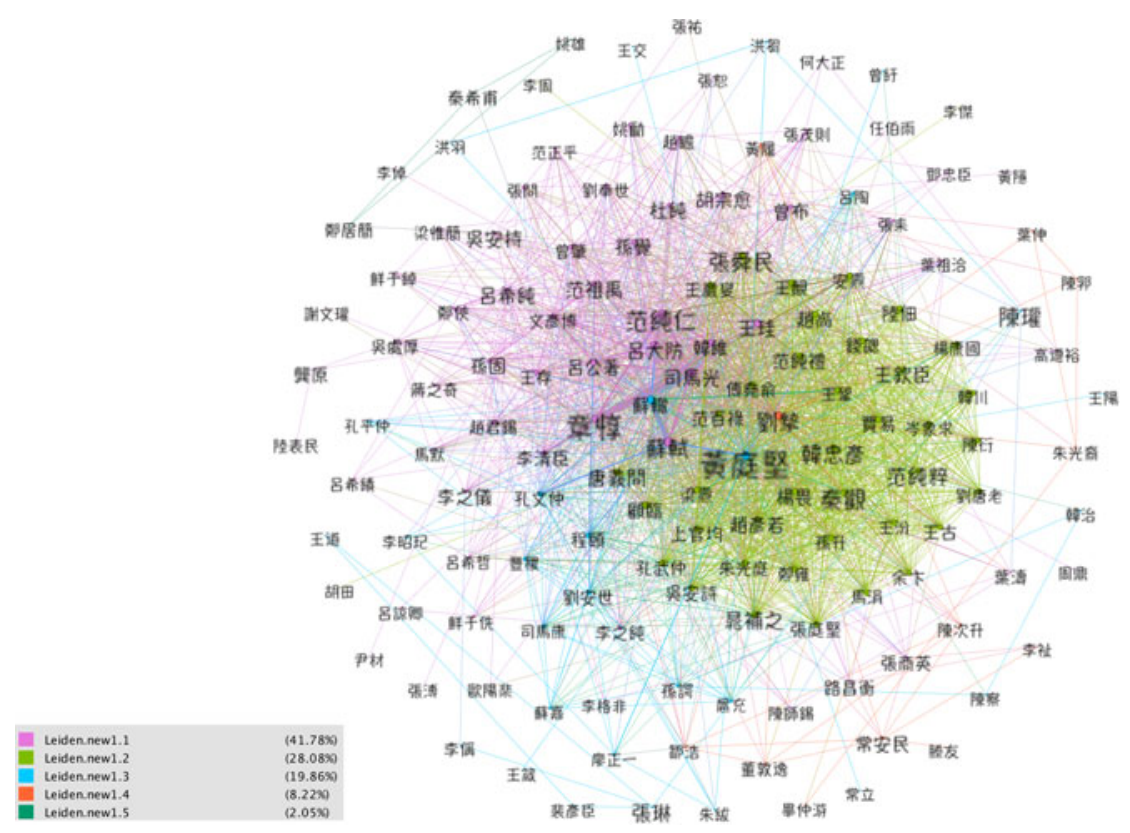

Figure 4. Network Visualization of Co-Occurrence Ties Among Those Listed on the Yuanyou list.

Note: The color of nodes and edges indicates Leiden clusters. The size of the nodes measures degree centrality (number of ties), with bigger nodes indicating a higher number of ties. The size of node labels (Chinese names of those on the list) indicates betweenness centrality, with bigger fonts corresponding to a higher betweenness centrality. The original files can be downloaded for further exploration in the accompanying dataset.

implemented hypergeometric statistical tests (separately for every list co-occurrence and shared toponym network). The hypergeometric test measures whether an overlap between edges in the co-occurrence network and edges in a native place network (based on having one's native place in the same prefecture) is statistically significant or whether it can be attributed to pure chance (Table 3a-b). Mathematically, under the null hypothesis that network ties are independent of shared location, the numbers of ties formed between actors with shared location are hypergeometrically distributed. The null hypothesis was rejected (adjusted p-value $<0.1$ ) in most cases, indicating, as expected, that local ties significantly contributed to list co-occurrence. Earlier scholarship on the Qingyuan group dismissed this attribute in the composition of the group as a whole on the basis that only some shared a common provincial background, but by focusing on absolute numbers rather than a comparison of the probable relation between two different kinds of ties may have ignored the visibility of native place as a factor in late twelfth-century political affiliations.

The differences between the different networks with regard to the statistical significance of overlap between co-occurrence in the work of peers and native ties are, however, less expected. Native ties are far more statistically significant for the Yuanyou network (Table 3a, Group 1). Even when we take the Yuanyou list in its entirety (Table 3a, Group 1 VAR), native ties are no less significant a predictor than in the case of the Qingyuan network of those blacklisted (Group 3 Anti Han Tuozhou) the fold enrichments are 1.13 and 1.17 respectively, but statistical significance is lower for the latter group and in both cases very low to borderline. 


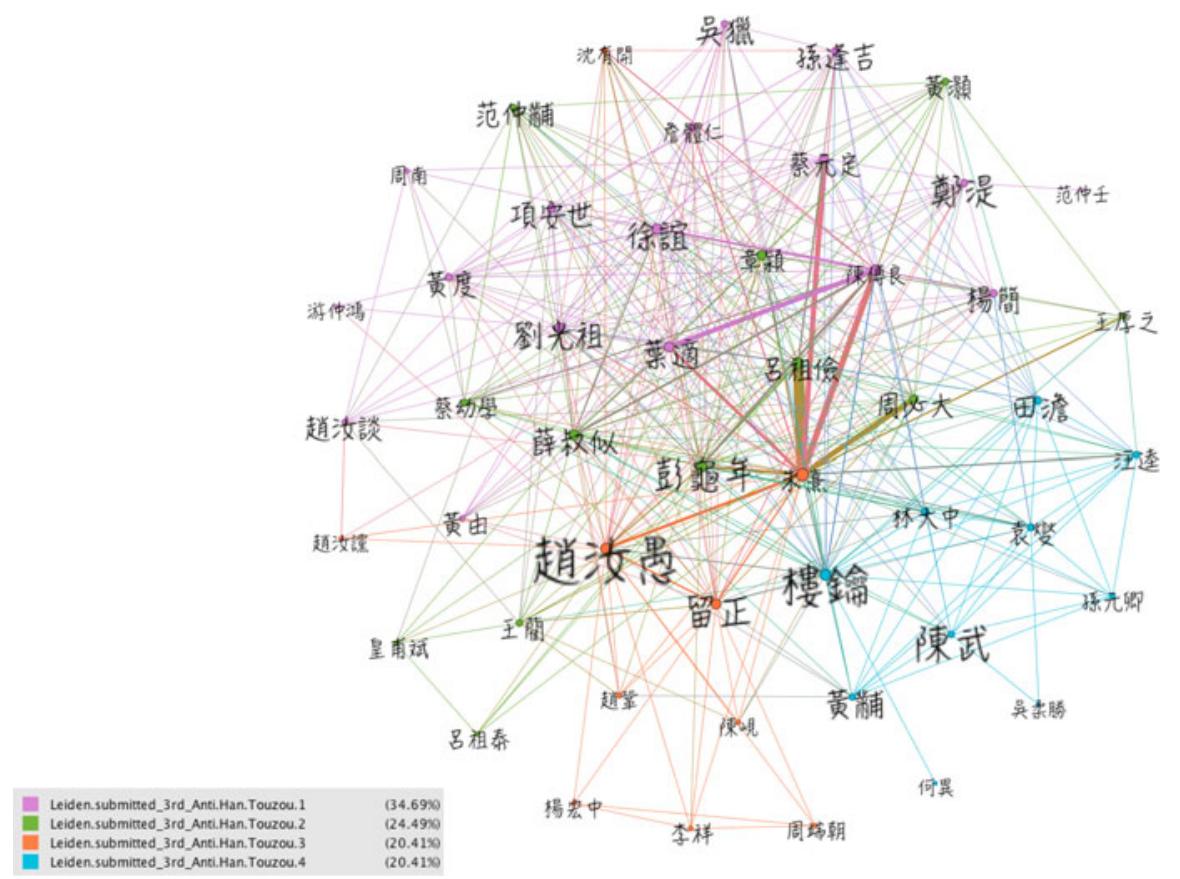

Figure 5. Network Visualization of Co-Occurrence Ties Among Those Blacklisted During the Qingyuan reign. Note: The color of nodes and edges indicates Leiden clusters. The size of the nodes measures degree centrality (number of ties), with bigger nodes indicating a higher number of ties. The size of node labels (Chinese names of those on the list) indicates betweenness centrality, with bigger fonts corresponding to a higher betweenness centrality. The original files can be downloaded for further exploration in the accompanying dataset.

To better understand which geographical centers gave rise to the shared-location networks, we computed the number of times each toponym served as a bridge between two actors in the network-that is, the number of shared-location ties attributed to the toponym. Observe that a single shared-location tie may be accounted by multiple toponyms (e.g., if a pair of actors shared more than one workplace during their careers). We thus further computed the number of times a toponym served as a unique bridge between two persons, i.e., the number of shared-location ties which are accounted for only by this toponym. To allow comparison between networks of different sizes we normalize the counts of bridges and unique bridges to a scale of [0-1] by dividing the counts for a given network by the number of potential ties in the network (which is $0.5^{*}|\mathrm{E}|{ }^{*}(|\mathrm{E}|-1)$ with $|\mathrm{E}|$ being the number of edges since these are undirected networks). We include these tables in the dataset accompanying this article. We also include an interactive table plotting the relative frequency of particular jurisdictions as the native place (Native column) and a place of official service (Posting column) among those included in each network.

Based on these data we can see that those listed on the False Learning blacklist as well as their alleged opponents were very likely to hail from the coastal circuit of Liang Zhe East; the former were also disproportionately likely to hail from Wenzhou Prefecture and the latter from Fuzhou Prefecture. By contrast, the Yuanyou group were likely to have come from a range of circuits but were especially likely to have 
Table 3a. Overlap between co-occurrence ties and native and work place ties: by prefecture

\begin{tabular}{|c|c|c|c|c|c|c|c|c|c|}
\hline \multirow[b]{2}{*}{ Co-occurrence network } & \multirow{2}{*}{$\begin{array}{l}\text { Shared } \\
\text { location } \\
\text { network }\end{array}$} & \multicolumn{4}{|c|}{ Hypergeometric distribution parameteres } & \multirow[b]{2}{*}{$\begin{array}{l}\text { Hypergeometric } \\
\text { fold enrichment }\end{array}$} & \multicolumn{3}{|c|}{ Statistical significance } \\
\hline & & Population & Desired & Picked & Successes & & $\mathrm{p}$-value & $\begin{array}{l}\text { Benjamini-Hochberg } \\
\text { adjusted p-value }\end{array}$ & $\begin{array}{l}\text { Bonferroni-Holm } \\
\text { adjusted p-value }\end{array}$ \\
\hline Group 1 & native & 10585 & 2156 & 291 & 103 & 1.74 & $1.15 \mathrm{E}-09$ & 4.97E-09 & $2.41 \mathrm{E}-08$ \\
\hline Group 3 EFA & native & 1128 & 347 & 31 & 16 & 1.68 & $1.13 \mathrm{E}-02$ & $1.96 \mathrm{E}-02$ & $1.36 \mathrm{E}-01$ \\
\hline Group 1 ES & native & 9591 & 1174 & 275 & 52 & 1.54 & $8.18 \mathrm{E}-04$ & $1.93 \mathrm{E}-03$ & $1.31 \mathrm{E}-02$ \\
\hline Group 3 ES & native & 2775 & 601 & 96 & 30 & 1.44 & $1.67 \mathrm{E}-02$ & $2.71 \mathrm{E}-02$ & $1.84 \mathrm{E}-01$ \\
\hline Group 1 EFA & native & 2145 & 586 & 56 & 21 & 1.37 & $6.01 \mathrm{E}-02$ & $7.81 \mathrm{E}-02$ & 4.32E-01 \\
\hline $\begin{array}{l}\text { Group } 3 \text { ES - Anti Han } \\
\text { Tuozhou }\end{array}$ & native & 1176 & 343 & 52 & 20 & 1.32 & $9.03 \mathrm{E}-02$ & $1.12 \mathrm{E}-01$ & $5.42 \mathrm{E}-01$ \\
\hline $\begin{array}{l}\text { Group } 3 \text { - Anti Han } \\
\text { Tuozhou }\end{array}$ & native & 1176 & 387 & 52 & 20 & 1.17 & $2.33 \mathrm{E}-01$ & $2.76 \mathrm{E}-01$ & $1.00 \mathrm{E}+00$ \\
\hline $\begin{array}{l}\text { Group } 3 \text { ES - Associated } \\
\text { with Han Tuozhou }\end{array}$ & native & 325 & 52 & 11 & 2 & 1.14 & $5.49 \mathrm{E}-01$ & $5.71 \mathrm{E}-01$ & $1.00 \mathrm{E}+00$ \\
\hline Group 1 VAR & native & 23005 & 10897 & 453 & 243 & 1.13 & $4.00 \mathrm{E}-03$ & $8.01 \mathrm{E}-03$ & $5.60 \mathrm{E}-02$ \\
\hline $\begin{array}{l}\text { Group } 3 \text { - Associated with } \\
\text { Han Tuozhou }\end{array}$ & native & 351 & 60 & 11 & 2 & 1.06 & $5.88 \mathrm{E}-01$ & $5.88 \mathrm{E}-01$ & $1.00 \mathrm{E}+00$ \\
\hline Group 1 ES & workplace & 9591 & 1174 & 722 & 174 & 1.97 & $2.76 \mathrm{E}-20$ & 3.58E-19 & $6.89 \mathrm{E}-19$ \\
\hline
\end{tabular}


Table 3a. (Continued.)

\begin{tabular}{|c|c|c|c|c|c|c|c|c|c|}
\hline \multirow[b]{2}{*}{ Co-occurrence network } & \multirow[b]{2}{*}{$\begin{array}{l}\text { Shared } \\
\text { location } \\
\text { network }\end{array}$} & \multicolumn{4}{|c|}{ Hypergeometric distribution parameteres } & \multirow[b]{2}{*}{$\begin{array}{l}\text { Hypergeometric } \\
\text { fold enrichment }\end{array}$} & \multicolumn{3}{|c|}{ Statistical significance } \\
\hline & & Population & Desired & Picked & Successes & & p-value & $\begin{array}{l}\text { Benjamini-Hochberg } \\
\text { adjusted p-value }\end{array}$ & $\begin{array}{l}\text { Bonferroni-Holm } \\
\text { adjusted p-value }\end{array}$ \\
\hline Group 1 & workplace & 10585 & 2156 & 731 & 291 & 1.95 & 4.97E-36 & $1.29 \mathrm{E}-34$ & $1.29 \mathrm{E}-34$ \\
\hline $\begin{array}{c}\text { Group } 3 \text { ES - Associated } \\
\text { with Han Tuozhou }\end{array}$ & workplace & 325 & 52 & 71 & 21 & 1.85 & 7.29E-04 & $1.90 \mathrm{E}-03$ & $1.24 \mathrm{E}-02$ \\
\hline $\begin{array}{c}\text { Group } 3 \text { - Associated with } \\
\text { Han Tuozhou }\end{array}$ & workplace & 351 & 60 & 81 & 25 & 1.81 & $3.10 \mathrm{E}-04$ & $8.94 \mathrm{E}-04$ & $5.57 \mathrm{E}-03$ \\
\hline $\begin{array}{l}\text { Group } 3 \text { - Anti Han } \\
\text { Tuozhou }\end{array}$ & workplace & 1176 & 387 & 159 & 89 & 1.70 & $9.21 \mathrm{E}-11$ & 4.79E-10 & 2.03E-09 \\
\hline Group 3 & workplace & 2850 & 702 & 474 & 195 & 1.67 & $1.76 \mathrm{E}-18$ & $1.52 \mathrm{E}-17$ & $4.22 \mathrm{E}-17$ \\
\hline $\begin{array}{l}\text { Group } 3 \text { ES - Anti Han } \\
\text { Tuozhou }\end{array}$ & workplace & 1176 & 343 & 159 & 75 & 1.62 & $1.72 \mathrm{E}-07$ & $5.58 \mathrm{E}-07$ & $3.27 \mathrm{E}-06$ \\
\hline Group 3 ES & workplace & 2775 & 601 & 455 & 158 & 1.60 & $1.08 \mathrm{E}-12$ & 7.04E-12 & $2.49 \mathrm{E}-11$ \\
\hline $\begin{array}{c}\text { Group } 3 \text { EFA - Associated } \\
\text { with Han Tuozhou }\end{array}$ & workplace & 171 & 47 & 51 & 21 & 1.50 & $8.45 \mathrm{E}-03$ & $1.57 \mathrm{E}-02$ & $1.10 \mathrm{E}-01$ \\
\hline Group 3 EFA & workplace & 1128 & 347 & 275 & 120 & 1.42 & $1.32 \mathrm{E}-07$ & $4.88 \mathrm{E}-07$ & $2.63 \mathrm{E}-06$ \\
\hline $\begin{array}{l}\text { Group } 3 \text { EFA - Anti Han } \\
\text { Tuozhou }\end{array}$ & workplace & 406 & 169 & 80 & 46 & 1.38 & $1.07 \mathrm{E}-03$ & 2.32E-03 & $1.61 \mathrm{E}-02$ \\
\hline Group 1 EFA & workplace & 2145 & 586 & 333 & 104 & 1.14 & $4.80 \mathrm{E}-02$ & $6.93 \mathrm{E}-02$ & $4.32 \mathrm{E}-01$ \\
\hline Group 1 VAR & workplace & 23005 & 10897 & 826 & 400 & 1.02 & $2.79 \mathrm{E}-01$ & $3.16 \mathrm{E}-01$ & $1.00 \mathrm{E}+00$ \\
\hline
\end{tabular}


Table 3b. Overlap between co-occurrence ties and native and work place ties: by route

\begin{tabular}{|c|c|c|c|c|c|c|c|c|c|}
\hline Co-occurrence network & $\begin{array}{l}\text { Shared } \\
\text { location } \\
\text { network }\end{array}$ & \multicolumn{4}{|c|}{ Hypergeometric distribution parameteres } & $\begin{array}{l}\text { Hypergeometric } \\
\text { fold enrichment }\end{array}$ & \multicolumn{3}{|c|}{ Statistical significance } \\
\hline Group 3 ES & native & 2775 & 601 & 27 & 153 & 1.34 & 7.07E-06 & 2.63E-05 & $1.41 \mathrm{E}-04$ \\
\hline Group 3 EFA & native & 1128 & 347 & 27 & 83 & 1.30 & $1.21 \mathrm{E}-03$ & $2.25 \mathrm{E}-03$ & $1.57 \mathrm{E}-02$ \\
\hline Group 1 & native & 10585 & 2156 & 27 & 161 & 1.29 & $1.85 \mathrm{E}-04$ & 5.34E-04 & 3.33E-03 \\
\hline Group 3 & native & 2850 & 702 & 27 & 168 & 1.27 & $5.37 \mathrm{E}-05$ & $1.75 \mathrm{E}-04$ & $1.02 \mathrm{E}-03$ \\
\hline $\begin{array}{c}\text { Group } 3 \text { ES - Associated } \\
\text { with Han Tuozhou }\end{array}$ & native & 325 & 52 & 27 & 11 & 1.13 & $3.78 \mathrm{E}-01$ & 4.27E-01 & $1.00 \mathrm{E}+00$ \\
\hline $\begin{array}{l}\text { Group } 3 \text { - Associated with } \\
\text { Han Tuozhou }\end{array}$ & native & 351 & 60 & 27 & 11 & 1.04 & $5.04 \mathrm{E}-01$ & $5.46 \mathrm{E}-01$ & $1.00 \mathrm{E}+00$ \\
\hline Group 1 VAR & native & 23005 & 10897 & 27 & 388 & 0.90 & $9.98 \mathrm{E}-01$ & $1.00 \mathrm{E}+00$ & $1.00 \mathrm{E}+00$ \\
\hline Group $1 \mathrm{ES}$ & workplace & 9591 & 1174 & 2888 & 564 & 1.60 & $1.68 \mathrm{E}-43$ & $2.18 \mathrm{E}-42$ & $4.20 \mathrm{E}-42$ \\
\hline
\end{tabular}


Table 3b. (Continued.)

\begin{tabular}{|c|c|c|c|c|c|c|c|c|c|}
\hline \multirow[b]{2}{*}{ Co-occurrence network } & \multirow{2}{*}{$\begin{array}{l}\text { Shared } \\
\text { location } \\
\text { network }\end{array}$} & \multicolumn{4}{|c|}{ Hypergeometric distribution parameteres } & \multirow[b]{2}{*}{$\begin{array}{l}\text { Hypergeometric } \\
\text { fold enrichment }\end{array}$} & \multicolumn{3}{|c|}{ Statistical significance } \\
\hline & & Population & Desired & Picked & Successes & & p-value & $\begin{array}{l}\text { Benjamini-Hochberg } \\
\text { adjusted p-value }\end{array}$ & $\begin{array}{l}\text { Bonferroni-Holm } \\
\text { adjusted p-value }\end{array}$ \\
\hline Group 1 & workplace & 10585 & 2156 & 2977 & 962 & 1.59 & $1.71 \mathrm{E}-76$ & $4.44 \mathrm{E}-75$ & $4.44 \mathrm{E}-75$ \\
\hline $\begin{array}{l}\text { Group } 3 \text { - Anti Han } \\
\text { Tuozhou }\end{array}$ & workplace & 1176 & 387 & 424 & 191 & 1.37 & $3.14 \mathrm{E}-11$ & $2.04 \mathrm{E}-10$ & $7.23 \mathrm{E}-10$ \\
\hline $\begin{array}{c}\text { Group } 3 \text { ES - Associated } \\
\text { with Han Tuozhou }\end{array}$ & workplace & 325 & 52 & 185 & 40 & 1.35 & $9.68 \mathrm{E}-04$ & $2.10 \mathrm{E}-03$ & $1.45 \mathrm{E}-02$ \\
\hline $\begin{array}{l}\text { Group } 3 \text { - Associated with } \\
\text { Han Tuozhou }\end{array}$ & workplace & 351 & 60 & 27 & 47 & 1.33 & $4.14 \mathrm{E}-04$ & $9.79 \mathrm{E}-04$ & $6.62 \mathrm{E}-03$ \\
\hline $\begin{array}{l}\text { Group } 3 \text { ES - Anti Han } \\
\text { Tuozhou }\end{array}$ & workplace & 1176 & 343 & 27 & 161 & 1.30 & 5.33E-07 & $2.31 \mathrm{E}-06$ & $1.12 \mathrm{E}-05$ \\
\hline Group 3 & workplace & 2850 & 702 & 27 & 407 & 1.30 & $2.95 \mathrm{E}-16$ & $2.55 \mathrm{E}-15$ & 7.07E-15 \\
\hline Group 3 ES & workplace & 2775 & 601 & 27 & 334 & 1.25 & $2.67 \mathrm{E}-10$ & 1.39E-09 & $5.87 \mathrm{E}-09$ \\
\hline $\begin{array}{l}\text { Group } 3 \text { EFA - Anti Han } \\
\text { Tuozhou }\end{array}$ & workplace & 406 & 169 & 27 & 100 & 1.12 & $1.77 \mathrm{E}-02$ & $2.55 \mathrm{E}-02$ & $1.59 \mathrm{E}-01$ \\
\hline Group 3 EFA & workplace & 1128 & 347 & 27 & 243 & 1.12 & 3.32E-04 & $8.64 \mathrm{E}-04$ & $5.65 \mathrm{E}-03$ \\
\hline $\begin{array}{c}\text { Group } 3 \text { EFA - Associated } \\
\text { with Han Tuozhou }\end{array}$ & workplace & 171 & 47 & 27 & 38 & 1.11 & $9.29 \mathrm{E}-02$ & $1.27 \mathrm{E}-01$ & 7.43E-01 \\
\hline Group 1 EFA & workplace & 2145 & 586 & 27 & 324 & 1.08 & $1.05 \mathrm{E}-02$ & $1.60 \mathrm{E}-02$ & $1.05 \mathrm{E}-01$ \\
\hline Group 1 VAR & workplace & 23005 & 10897 & 27 & 1562 & 0.93 & $1.00 \mathrm{E}+00$ & $1.00 \mathrm{E}+00$ & $1.00 \mathrm{E}+00$ \\
\hline
\end{tabular}


come from two prefectures in the metropolitan region: Kaifeng and Henan (or Luoyang). Strikingly, 120 ties in the shared-native jurisdiction network of the Yuanyou group are attested on account of Kaifeng Prefecture, comprising 1.1 percent of the potential edges (realized or not) in the shared-native network. Moreover, in all of these instances Kaifeng served as a unique bridge between the actors. Apart from the capital, only one other toponym served as a substantial bridge in the Yuanyou shared-native network: Luoyang accounted for 78 ties, 0.7 percent of the potential edges, 75 of these as unique bridge. All other jurisdictions accounted for much smaller fractions of the shared-location ties.

The latter finding confirms what earlier scholarship has said about the predominance of the capital region in the makeup of the Northern Song political elite. From the available postings data we can similarly conclude that those in the Yuanyou group were more likely to have experience in the capital region and the adjoining circuits, especially Yongxing in the west; in the Qingyuan case service in some circuits (Jiangnan East and West, Liang Zhe East and West, and Fujian) was again more highly correlated with affiliation with either of the two opposing groups.

With regard to the hypothesis about a shift from vertical court-centered ties to horizontal local ties in twelfth-century factionalism, we underscore that native place ties do not necessarily translate into "locally based and horizontally organized" networks. The Qingyuan network was admittedly denser than other networks at the local level, but it was obviously also a court-centered network with most having held court titles and positions, and it had an evidently hierarchical structure.

What significance should we attach to the hierarchical structure of the Qingyuan network? We propose that the hierarchical nature of the network reflects the fact that it had strong extensions into the provinces and was shaped by provincial ties including both native place ties as well as shared workplace ties (the probability for the latter is higher than one would expect also in the Qingyuan network, Table 3a workplace data). Zhu Xi, for example, maintained an active correspondence with associates in the provinces while at court, and wrote associates at court while in the provinces about matters relating to intellectual as well as all manner of policy and political matters-including what to prioritize in meetings with the emperor while he and others were serving as lecturers to the emperor. ${ }^{74}$ One could interpret this as a flattening of vertical bureaucratic ties, but the network hierarchy suggests that such practices and the rhetoric of "our group" (wudang 吾黨) should not blind us to the new kinds of hierarchies that came with Learning of the Way politics and horizontal networking: Learning of the Way advocates like Zhu Xi did not merely build local and regional ties for their own sake, he leveraged them in court politics as well as among gentlemenscholars in the provinces, and it appears, as we shall see below, there were few brokers like him who were perceived to have this kind of leverage.

\section{Sampling the False Learning List}

Because historians have come to see the Learning of the Way, and by extension the Qingyuan network, as an embodiment of a more general trend towards elite investment in local ties and horizontal networking in the Southern Song Dynasty, we decided to check how the contemporary record would construe ties among a sample of elite men with career backgrounds similar to those in the Qingyuan group. Sampling is

\footnotetext{
${ }^{74}$ Hilde De Weerdt, "Empire and the Institutions and Practices of Classicizing Learning," in progress.
} 
unusual, and often impossible or undesirable, in historical research; here we briefly set out how we constructed the sample and explain our preliminary findings about methods and results.

We gathered data on dates, government positions, and method of entry (examination title or not) for all those on the False Learning list and for those listed as the opponents of False Learning for whom we have biographical information in CBDB ( 55 out of 59 in the former case, and 34 out of 37 in the latter). We set three criteria for a match between any member on the list and any record in CBDB. First, the index year had to fall within a 15-year range, thus 15 years earlier or later than a person on the False Learning lists. Second, career similarity was calculated by the overlap in unique government positions. ${ }^{75}$ Third, the entry method had to be identical. We selected these criteria so as to be able to identify a group similar to and contemporary with the two False Learning groups which we had used in the network analysis above. For 73 individuals on the list we found one or more candidates that could match all criteria; for 78 we found candidates that matched the first two criteria only. The final sample consisted of the 109 highest ranked matches (using only candidates that could match all criteria), slightly larger than the original in order to maximize the number of hits in the corpus and arrive at a comparable dataset.

We subsequently ran the list of names and alternate names for the 109 individuals in the sample group against the original corpus we had compiled for the Qingyuan group. The curated dataset consisted of only 15 nodes and 28 edges, making any further analyses more or less meaningless. We cannot draw firm conclusions on the basis of one sample, but we can offer one potential explanation for the sparseness or even absence of perceived ties among the sample group when compared to the Qingyuan group analyzed above. This may suggest that those associated with the Learning of the Way who were at the core of the Qingyuan network were in the twelfth century not necessarily representative of the larger cultural and political elite. The surviving record was evidently biased towards them, both the historical record as it has been handed down since the thirteenth century, and the broader literary record-they were mainly responsible for this as well. It may also be the case that they proved singularly successful in leveraging local and regional ties at court, whereas many of their contemporaries continued to operate outside of hierarchically organized coalitions that linked local clusters to the court. Did the Learning of the Way group then set the stage for scholar-official elite networks and political networking in later imperial Chinese history by developing and maintaining hierarchical networks that tied local communities to the court?

\section{An Absent Network}

In addition to the Yuanyou and Qingyuan lists compiled at the beginning and the end of the twelfth century, a third list was compiled reflecting mid-century politics. In 1141 the Song court signed a peace treaty with the Jin court. The Jin Empire thereby attained the Song court's acknowledgment of its occupation of the former capital of the Song as well as most former Song territories north of the Huai and Yangzi rivers. The treaty could be considered the major achievement of the then ruling councilor Qin Gui and Emperor

\footnotetext{
${ }^{75}$ The career similarity is measured by office only; it was impossible to find sufficient candidates within a fifteen-year range if the location of local offices was added to the calculation. Candidates are ranked by the overlap in unique offices which we calculated using Jaccard index (https://en.wikipedia.org/wiki/ Jaccard_index).
} 
Gaozong, as it also guaranteed the Song court's hold over the south where it had established a new, albeit explicitly temporary, capital in Lin'an or Hangzhou. ${ }^{76}$ The peace treaty could also count on strong opposition, however. The anonymous Southern Song text The Right Opinion on the Shaoxing Reign (Shaoxing zhenglun or 紹興正論) contains a list of thirty men who had allegedly been opposed to the settlement and ousted by Qin Gui for this reason. We examined whether those on this list formed a dense network of early adopters of the Learning of the Way and/or a loose alliance of political allies of the former Councilor Zhao Ding who rejected a peace treaty with the Jurchens and who featured on the list. We used the same methodology, analyzing how ties between these men were reported in the work of contemporaries.

We took 1142 or the year following the treaty as the presumed year of the ousting. ${ }^{77}$ The corpus of documents by authors who were active in the period covering 1112-1172 consists of 47,040 documents by 2,710 authors. After running the names and alternate names of the thirty listees (only four of which do not appear in CBDB) through this corpus, we compiled a raw dataset of 3,745 mentions in 2,262 documents by 433 authors. From this we obtained a raw network dataset of 353 co-occurrences. Because many ties were weighted at 1 , representing a single mention of a co-occurrence, we set cutoffs at weights higher than 1, 2, 3, and 5. In contrast to the Yuanyou network, the 1142 network dissolved at these low cutoffs. Source bias may help account for the lower number of mentions. Given, however, that we have a corpus comparable in size, the sharp difference between the raw results of the Yuanyou and Shaoxing 紹興 (referring the reign period 1131-1162 from which this list presumably dates) groups may suggest that contemporaries did not perceive strong connections between those on the list. There is no evidence of a dense network and neither of strong ties within cliques of an intellectual or political nature. Even though contemporary authors drew connections between some of the more prominent political and military figures on the list, including Zhao Ding, Zhang Jun 張浚 (1097-1164), and Hu Quan 胡銓 (1102-1180), for example, we may conclude from the results of the raw dataset that they did not perceive a coordinated political or intellectual opposition. This list probably reflected a series of dismissals related to opposition to Qin Gui's pro-peace stance, confirming the perception that it was compiled retrospectively on the model of the Yuanyou list. Because we see in the raw dataset an absence of connectivity, we did not pursue the further data curation and network analysis performed on the Yuanyou and Qingyuan datasets. With this we also want to underscore an important methodological point, namely, that with network analysis we can detect the absence or breakdown of relationships just as well as connectivity.

\section{On Different Kinds of Networks: A Late Imperial Order?}

Social networks have been a central focus in a rich and growing secondary literature covering the Song period since the 1980s. Historians have traced transformations in elite marriage networks and related those to changing residential patterns, and to trends in

\footnotetext{
${ }^{76}$ Herbert Franke, "Treaties between Sung and Chin," in Études Song: In memoriam Étienne Balazs, edited by Françoise Aubin (Paris: Mouton, 1970), 55-84.

${ }^{77}$ Because major political opponents of Qin Gui were demoted or exiled in view of their non-compliance with the peace settlement before 1142, we take the year 1142, which somehow demarcates the end of the anti-Qin Gui faction, as the presumed year of the ousting. Japanese scholar Teraji Jun argues that the year 1142 was a watershed, signifying the beginning of an authoritarian structure under Qin Gui's chief councillorship. See Teraji Jun, Nan Song chuqi zhengzhishi yanjiu (Shanghai: Fudan daxue, 2016), 16-17.
} 
office-holding and occupational preferences. ${ }^{78}$ More recently we have examined shifts in the geographical and social distribution of elite communication networks in the context of the broader social transformations of the period covering the late Tang Dynasty through the early Southern Song (eighth to twelfth centuries). ${ }^{79}$ Below we offer some further observations on a key question that has yet to be addressed in the literature: how do the various types of networks discussed in the recent literature and their dynamics relate to each other? Do they reinforce each other or do trends in one type of network compensate for trends in another? Do networks develop in similar or opposite directions over time? Do they overlap or do elites do different things in different types of networks, for example establishing local ties through marriage and negotiating careers through political or communication networks at court? Do the relationships between different types of networks constitute some kind of a late imperial order or do we see them developing according to different rhythms depending on social, local, or regional factors?

Modern historians have highlighted two major shifts in marriage networks between roughly 700 and 1200. Nicolas Tackett has argued on the basis of a prosopographical study of 3,329 epitaphs that Tang elites were divided into two largely non-overlapping groups: a "national" elite based in the metropolitan area covering the capitals of Luoyang and Chang'an and the area between them, and a provincial elite whose power was restricted to the local level. The former group dominated office-holding at court and at the provincial level and perpetuated their status through the recognition of family status and intermarriage. Tackett's network of intermarriages among old aristocratic families in the capital showed that a very small number of families were at its centre. By the late ninth century this system was violently brought to an end when the Huang Chao 黃巢 rebellion (874-84) led to the decimation of the old aristocratic families in the Tang metropole. ${ }^{80}$ Earlier, Robert Hymes proposed a similar picture of the Northern Song elite on the basis of an analysis of the marriage relations in Fuzhou 撫 州, Jiangxi. Through the eleventh century elite families mainly contracted marriages with other bureaucratic families outside of their native prefectures, and they did so in order to strengthen their opportunities to maintain bureaucratic office. The key difference with the Tang was that office-holding rather than aristocratic lineage had become the defining feature of the metropolitan elite. Hymes further argued that over the course of the twelfth century the marriage networks of Fuzhou elite families

\footnotetext{
${ }^{78}$ For earlier work on the nature of changes between the Northern and Southern Song, see Robert M. Hartwell, "Demographic, Political, and Social Transformations of China, 750-1550," Harvard Journal of Asiatic Studies 42.2 (1982), 365-442; Robert Hymes, Statesmen and Gentlemen: The Elite of Fu-chou, Chiang-hsi, in Northern and Southern Sung (Cambridge: Cambridge University Press, 1986). For an overview of East Asian and European language scholarship, see Luo Yinan, "A Study of the Changes in the 'Tang-Song Transition Model'," Journal of Song Yuan Studies 35 (2005), 99-127. Representative examples of different kinds of critiques of the localist turn include Beverly Bossler, Powerful Relations: Kinship, Status, and the State in Sung China (960-1279) (Cambridge, MA: Harvard University Asia Center, 1998); Lee Sukhee, Negotiated Power: The State, Elites, and Local Governance in Twelfth- to Fourteenth-Century China (Cambridge, MA: Harvard University Asia Center, 2014). For the pre-Song period see especially Nicolas Tackett, The Destruction of the Medieval Chinese Aristocracy (Cambridge, MA: Harvard University Asia Center, 2014).

${ }^{79}$ De Weerdt, Information, Territory, and Networks: The Crisis and Maintenance of Empire in Song China (Cambridge, MA: Harvard University Asia Center, 2015).

${ }^{80}$ Tackett, The Destruction of the Medieval Chinese Aristocracy, esp. chapter 3; De Weerdt, "Review of The Destruction of the Medieval Chinese Aristocracy by Nicolas Tackett," Journal of Interdisciplinary History 46.4 (2016), 623-25.
} 
changed dramatically: few then contracted marriages outside of their prefectures, implying that their marriage networks had become local in scope. ${ }^{81}$

Even though many have raised objections both regarding the evidence used for Fuzhou and the broader hypothesis, ${ }^{82}$ many studies attest to a greater investment in local ties among Southern Song elites. Recently Chen Song, for example, has shown in a comparison of the marriages of two cohorts of prefectural officials in 1040 and 1210 that the later cohort was far less likely to marry outside the macroregion within which their native prefecture fell than the earlier cohort. In the 1210 s prefects were far less likely to intermarry, whereas in the 1040s prefects from the north tended to dominate in the economy of marriage. ${ }^{83}$ In sum, over the course of the Song Dynasty marriage networks among the political elite tended to become more regional and less capital-oriented.

Research on communication networks is comparatively scarcer and newer. Based on a series of case studies, Hilde De Weerdt has proposed that informant networks reported in twelfth- and thirteenth-century notebooks tended to become socially more inclusive, and that their geographic backgrounds covered a broad transregional space. ${ }^{84}$ The broad geographic coverage of the communication networks of Southern Song political elites is also evident in case studies of the spatial distribution of correspondence networks. It is well known that Zhu Xi kept up an extensive correspondence with scholars and officials and that this network covered the capital and counties throughout the Song Empire. The same is true for a scholar-official like Yang Wanli 楊萬里 (1127-1206), who was not implicated in the Qingyuan factional struggles but who had some sympathy towards the Learning of the Way. The letters sent from his home in Jizhou 吉州 predominantly went to addressees in the capital and also covered a range of other locations. ${ }^{85}$ In sum, over the course of the Southern Song Dynasty the scholar-official elite commemorated in their collected works and notebooks communication networks that were broadly transregional in geographic scope and continued to exhibit a strong capital- and court-focused orientation.

De Weerdt proposed that the broad transregional scope of literati communication networks in the Southern Song could in part compensate for the reduced reach of marriage networks. In other words, as political elites moved out of the Northern Song metropole and settled down in their native places or the places to which their families had recently migrated after the occupation of the north, they intermarried locally or regionally to build local coalitions. At the same time elite families continued to pursue

\footnotetext{
${ }^{81}$ Hymes, Statesmen and Gentlemen, esp. chapter 3.

${ }^{82}$ Most critical on both of these accounts is Bao Weimin 包伟民, “Jingyingmen difanghua le ma? Shilun Han Mingshi zhengzhijia yu shenshi yu difangshi yanjiu fangfa” 精英们地方化了吗：试论韩明士政治家 与绅士与地方史研究方法, Tang yanjiu 唐研究 2005.253-71.

${ }^{83}$ Chen Song, "Governing a Multicentered Empire: Prefects and Their Networks in the 1040s and 1210s," in State Power in China, 900-1325, edited by Patricia Buckley Ebrey and Paul Jakov Smith (Seattle, WA: University of Washington Press, 2016), 101-52; De Weerdt, "Review of State Power in China, 900-1325, edited by Patricia Buckley Ebrey and Paul Jakov Smith,” Journal of Chinese Studies 68 (2019), 276-80.

${ }^{84}$ De Weerdt, Information, Territory, and Networks, esp. chapter 7; De Weerdt and Brent Ho, "Information, Territory, and Networks: Accompanying Data and Visualization Site" (2016), http://chinese-empires.eu/reference/information-territory-and-networks/.

${ }^{85}$ For a preliminary analysis of the corpus of Yang Wanli’s letters, see De Weerdt, "Tang Song shi yanjiu Zhong de shuzihua yuwenxue” 唐宋史研究中的數字化語文學 [The Uses of Digital Philology in Tang-Song History] (tr. Lincoln Tsui), Tang Song lishi pinglun 唐宋歷史評論 3 (2017), 3-19.
} 
examination degrees and office for at least some of their offspring through networks that were transregional in scope and that connected them to the capital.

We interpret the political networks embedded in the twelfth-century faction lists in this light. The network capturing the perceptions of ties among the 309 men listed on the 1104 blacklist represents, at its core, a dense network of relations among peers focused on the metropole; local connections outside of the capital are far less visible to us-this may in part be due to the nature of the transmitted record. It thus fits with Hartwell's and Hymes's characterizations of the Northern Song capital elite. The social, communication, and political networks of this elite overlapped and reinforced each other.

In contrast, the network capturing the perceptions of ties among the 59 men registered on the Qingyuan blacklist was a hierarchical network among smaller clusters who were linked to some highly influential figures. Local connections were a far more visible factor in this clustered network. These findings fit in with Hymes's and Chen's findings that the Song bureaucracy had become southernized and multicentered: no place, not even the capital, dominated as the place of origin or registered residence of officialdom. Local and regional marriages made sense within such a world, and broader coalitions could be built by other means. The communication networks of twelfth-century literati and the political coalitions captured in the Qingyuan ban did not overlap with the marriage and immediate social networks of their main protagonists but extended outward from them. These networks were built on local and regional associations that also provided access to court connections. The Neo-Confucians at the core of Qingyuan group were thus not seeking authority outside the court but rather sought to translate local and regional authority gained through their investment in local reform programs into authority at court and into empire-wide reform-this was most likely also one of the reasons why they consistently ran afoul of other forces at court throughout the late twelfth century. Some among those on the list were, moreover, explicitly theorizing such a view of the local. The Yongjia scholars, who formed a cluster and who were in the view of some scholars key targets, ${ }^{86}$ "articulated local interests theoretically. Rather than identifying with the particular interests of their place of origin, they discussed local interests in general and in relationship to centralizing policies." ${ }^{87}$ To many scholars the local orientation of Learning of the Way scholars became paradigmatic for the remainder of late imperial Chinese history; in this view social, communication, and political networks were thus realigned into a new imperial order in which local elites, licensed by the court through participation in the examinations, collaborated with local and central government in governing local communities. The Qingyuan episode and the results of our sampling exercise suggest, however, that the Learning of the Way reformers, sometimes understood as committed early Protestant reformers, constituted a far more organized and formidable coalition of local reformers than many of their later successors.

\section{Historical and Methodological Conclusions}

We have employed a range of computational methods to address a key question in Chinese political history: were faction lists such as the Yuanyou, Shaoxing, and

\footnotetext{
${ }^{86} \mathrm{Li}$, "Zhou Bida, Zhao Ruyu, and Yongjia shiren."

${ }^{87}$ De Weerdt, Competition over Content, 382.
} 
Qingyuan lists the product of factional rhetoric, the ire of lone councilors, later victimization narratives, or did they represent political and intellectual factions of some kind? We compared current hypotheses about the formation of each list to our findings derived from a network analytical reading of the ties amongst those on the list as reported in contemporary prose collections. The answer is different in each case. The 1104 list appears to represent at its core a large connected metropolitan network; the Shaoxing list does not appear to represent a coalition and may reflect a victimization narrative based on a series of reprisals under the regime of Councilor Qin Gui; and, the Qingyuan blacklist a hierarchically organized coalition of intellectual and political clusters that are internally densely connected. Based on a comparison of the network structure of the reported ties and the significance of shared locality in it, we argued that these networks tie in with previous findings that elite social networks shifted from being capital-based bureaucratic peer networks to broader local or regional associations. From the hierarchical nature of the later Qingyuan network, we further inferred that the horizontal and local/ regional dimensions of later twelfth-century literati networking were linked to vertical access to the court. This realignment of literati social, communication, and political networks may foreshadow a new imperial order that became the norm in the Ming and Qing Dynasties.

In the context of this thematic issue on digital history we also want to offer some further reflections on the limits and affordances of the computational methods we used for historical research. Fears about quantitative history have a long history and remain virulent. ${ }^{88}$ We see the relationship between quantitative, philological, social scientific, and critical approaches as dialogical and not competitive. History is not a zerosum game where one method can replace another. The macroscale analytical approach used here produces a different kind of academic narrative and understanding of historical events than a microscale close reading of exchanges that reportedly took place in the course of factional struggle.

A comparative computational approach is fruitful, and perhaps inescapable, in macroscale analysis of extensive text corpora. It offers a language to formulate hypotheses on macroscale patterns, and a statistical framework to test their validity. Here, these benefits are reflected in the capacity to include hundreds of names in an examination of a very extensive corpus of texts, the translation of hypotheses concerning social organization into social network terms, the testing of various hypotheses that have been proposed on the basis of case studies, testing against our own confirmation bias, and the addition of a probabilistic perspective to earlier assessments of the significance of particular attributes. Cross-disciplinary collaboration was key in this process. But there are costs and hazards. The macroscale and computational approach used here comes with a degree of uncertainty and a margin of error: in the compilation of a large corpus, the collection of alternate names, the annotation of the corpus, and the analysis of the network data there are omissions and mistakes, and decisions as to what to include and exclude will impact the interpretation of the results. This is as much a matter of expectations of course as it is of different standards. Similar problems are inherent in the selection and close reading of texts, but historians tend to read social scientific discourse as more definitive. Nonetheless, methods adopted from the exact sciences do not bear exact results

\footnotetext{
${ }^{88}$ De Weerdt, "Digital Interpretations," in Communication and Empire: Chinese Empires in Comparative Perspective, February 5, 2014, http://chinese-empires.eu/blog/digital-interpretations/.
} 
when applied to humanistic inquiry. We view conclusions drawn based on computational analyses, such as the ones offered here, not as definitive answers but rather as contributions to a line of research, which, like conclusions drawn based on traditional historical methods, would be subject to critical scholarly examination. For example, the statistical models we employed rely on assumptions that one could argue against. A computational methodology does not preclude critical discourse, and its results, such as the conclusions we offered, may be adapted or outright challenged by future research.

The critical close reading of select primary sources remains at the heart of historical research, and in this regard macroscale digital approaches present opportunities as well as problems. The macroscale approach is to many historians only of value if it can be linked to meso- and microscales. The analysis of the faction lists, for example, raises questions about individuals and coteries of individuals that can only be addressed at these lower levels. A more difficult and unresolved problem in the current research landscape is how to bring the contextualization that a macroscale annotation or analysis can offer to bear on the digital text archives many of us use.

\section{Appendix}

\section{Descriptive Statistics}

\section{Figure 1: Density vs. Clustering Coefficient}

The figure demonstrates the differences between network density, global clustering coefficient (GCC; also called transitivity), and local clustering coefficients (LCCs) via two toy (i.e., model) undirected networks. A network's density is the ratio of realized ties out of the number of possible ties. Network A has $n=10$ nodes, and the number of possible edges is therefore (as it is an undirected network) $10 * 9 / 2=45$. The network has 9 edges, and its density is consequently $9 / 45=20$ percent. A similar computation shows that network $B$ also has a density of 20 percent.

However, it is apparent that the two networks have very different clustering patterns. Intuitively, in highly clustered networks the existence of ties $(A, B)$ and $(A, C)$ strongly suggests a third tie $(A, C)$. For example, in the case of friendship ties, ${ }^{89}$ if $\mathrm{A}$ is a friend of $\mathrm{B}$ and $\mathrm{B}$ is a friend of $\mathrm{C}$ then it is likely that $\mathrm{A}$ is also a friend of C. Quantitatively, the GCC is the number of realized closed triads over the number of potential triads, and it ranges between 0 and 1 (both inclusive). For example, network A has no closed triads, it therefore has GCC $=0$; network B has only one triad, and it is closed, hence it has $\mathrm{GCC}=1$.

These networks also demonstrate that the GCC might not fully capture the disparity between nodes when actors have very different positions within the network. In such cases one may refer to the local clustering coefficient (LCC), which was defined by Watts and Strogatz. ${ }^{90}$ For every node $v$, it equals the density of the subnetwork composed only of $v$ 's neighbors while omitting $v$. The value is undefined for nodes without neighbors or with exactly one neighbor (and we define it as 0 for the purpose of taking the mean LCC in Table 1). Intuitively, the LCC of a vertex $v$ quantifies the extent by which $v$ serves as the sole bridge between its immediate neighbors.

\footnotetext{
${ }^{89}$ The term "clustering" is widely used despite its ambiguity. It may refer to the transitive property as described here and in the section "Statistical Comparison of Quantitative Network Properties," but also to the partition of the network into communities-groups of nodes that are intensively inter-connected among themselves but only loosely connected to the rest of the network-as in the section "Community Detection and Hierarchy within Community."

${ }^{90}$ Duncan J. Watts and Steven H. Strogatz, "Collective Dynamics of Small-World Networks," Nature 393 (1998), 440-42.
} 


\section{Figure 2: Empirical Cumulative Distribution Function (CDF) of the LCC}

Whereas the GCC is a single number, the LCCs are defined per node. and studying them together (in mathematical terms, studying their distribution) illuminates aspects of node-to-node disparity that cannot be captured by a single number. Figure 2 demonstrates the differences between the LCC distributions for three of the studied networks. It is a CDF plot, which is common in descriptive statistics, with the term empirical indicating it is based on a finite sample of data.

The LCC for any node ranges between 0 and 1 (both inclusive), and this is the range of the $\mathrm{x}$-axis. The $\mathrm{y}$-axis for some value $L$ is defined as the ratio of nodes $v$ such that $L C C(v) \leq L$. For instance, the ECDF of Group 1 (solid line) contains the point $(0.623,0.75)$, indicating that 62.3 percent of the vertices of Group 1 had an LCC of 0.75 or less.

\section{Statistical Testing}

Intuitively, a statistical test seeks to determine whether the collected data (often referred to as observed data) fits with some supposition, or whether it is so incongruent as to forcefully suggest the supposition is untrue. The supposition is the null hypothesis and if the data is incommensurate with it then we reject the null in favor of an alternative hypothesis. For example, assume we believe that the we have a fair coin in hand and we flip it 100 times, resulting in 55 heads and 45 tails. The null hypothesis is that the coin is fair (implying we expect it to result in equal number of heads and tails flips), and the data does not strongly suggest that this is not the case. However, should we flip the coin 100 times and find the outcome was always tails, we will reject the null as totally incongruent with our original supposition (even though we cannot know for sure! It is improbable, yet not impossible, that 100 tosses of a fair coin will result in 100 tails).

To quantify the degree to which the observed data is commensurate with the null hypothesis, we define a null model and compute a p-value, which can intuitively be thought of as the probability of observing data similar to one in hand should the null model be true (importantly, note that this is not a mathematically accurate definition; in this appendix, we prioritize legibility over mathematical rigor). A small p-value (typically $\mathrm{p}<0.05)$ is considered as statistically significant evidence that the null model is incommensurate with the data.

We have here presented three analyses that demonstrate three varieties of null models used in statistical testing.

\section{Empirical Null (Table 2)}

A simple comparison between the numerical properties of two networks might be uninformative. The observed difference might be arbitrary and not indicative of a fundamental difference between the networks. From a statistical standpoint, we are asking whether the differences between two networks can be a mere coincidence, or whether the coincidence is so unlikely that it is rather more likely there is something fundamentally different between them. The problem is compounded in comparisons of networks of considerably different sizes, when the observed difference could be an artifact of their size differences.

A null model for a social network should account for the various properties that are characteristic of human interaction and do not arise randomly (e.g., transitivity). Intuitively, we would like to keep all these properties while eliminating only the effects of the size difference. We achieve this through use of an empirical null, ${ }^{91}$ which randomizes the tested data property, while keeping other properties intact.

Given a large network A and a small network B we define the null model by randomly subsampling the larger network. Denote by $b$ the number of nodes in network B. We repeat $N=1,000$ times the following procedure:

1. Randomly select a subset $b$ nodes in $A$, and keep only edges between these nodes.

2. Compute the desired network properties (density, GCC, etc.) on the new network.

\footnotetext{
${ }^{91}$ Bradley Efron and R.J. Tibshirani, An Introduction to the Bootstrap (London: Chapman \& Hall/CRC, 1993).
} 
The collection of 1,000 networks is an empirical null, a statistical representation of "how we believe network A should have behaved had we eliminated the size difference" which is comparable to network B. This allows deriving a p-value.

\section{Hypergeometric Null (Table 3)}

Occasionally, the null model can be described analytically without requiring empirical randomization. Such is the case of overlaps between the co-occurrence and shared-location networks. A well-studied case in probability is the following: Assume one has an urn with $b$ black balls and $w$ white balls. One randomly draws $k$ balls from the urn-how many black balls did one draw? The number of black balls is said to be hypergeometrically distributed and this allows an accurate computation of the p-value. In our case, the urn of balls is the set of all the possible edges of the co-occurrence network (the population in Table 3), those that are realized and those that are not. A black ball is a realized co-occurrence edge (desired). We pick balls randomly, equated to inspecting the edges of a given co-location network (picked) and determine how many overlapping edges we find (the number of black balls in the draw, successes). An overlapping edge is a list co-occurrence that can be explained by shared location, and a small p-value indicates that the co-occurrence ties are unlikely to have arisen by chance, irrespective of the shared location network.

The four integer quantities described thus far (population, desired, picked, successes) form columns 3-6 in Table 3 and allow computing the hypergeometric fold-enrichment (column 7) and p-value (column 8). The fold-enrichment measures the degree by which the overlap exceeds expectation and is comparable between networks (rows in Table 3). For instance, the top row of Table 3a indicates that the 103 observed overlaps (successes) constitute 74 percent more (fold enrichment $=1.74$ ) than one would expect by chance (i.e., under the null model).

The $\mathrm{p}$-value is a measure of statistical significance as described above. Smaller $\mathrm{p}$-values indicate that the edge overlap between the co-occurrence and shared location networks in a particular comparison (row in Table 3) is substantial enough to deduce that it did not arise by chance. The p-values are denoted in standard scientific notation that allows efficient representation of very small numbers. For example, in the top of Table $3 \mathrm{a}$ the p-value $1.15 \mathrm{E}-09$ is to be read $1.15^{\star} 10^{-9}$ (which equals 1.15 divided by the number composed of the digit 1 followed by nine zeros).

When multiple tests are conducted (as in the case of Table 3) the p-value cannot be read at face value and requires adjustment. The result of two adjustment methods are given in columns 9 and 10, explained below.

\section{Knowledge-Based Null (In the Section "Sampling the False Learning List")}

We reasoned that the comprehensive curated data in CBDB could allow a non-standard, yet informative analysis. Instead of the widespread statistical methods of resampling or subsampling observed data, ${ }^{92}$ the CBDB presents an opportunity to sample a parallel network based on predefined criteria. This results in a unique type of null model-a hypothetical social network of contemporary peers of the studied actors.

\section{Multiple Comparisons and Adjusted P-Values (Benjamini-Hochberg, Holm-Bonferroni, and Bonferroni Methods)}

An important caveat to statistical testing is the challenge of multiple comparisons. ${ }^{93}$ The higher the number of hypotheses being tested, the higher is the probability for false rejection of the null hypothesis (i.e., a small p-value being observed by pure chance, while the null hypothesis stands and should not be rejected). Methods for controlling the number of false-positive rejections are characterized by a tradeoff between conservativeness (avoidance of rejecting true nulls) and statistical power (capability to reject false nulls).

\footnotetext{
${ }^{92}$ Efron and Tibshirani, An Introduction to the Bootstrap.

${ }^{93}$ Bradley Efron and Trevor Hastie, Computer Age Statistical Inference: Algorithms, Evidence, and Data Science (Cambridge: Cambridge University Press, 2016), 271-90.
} 
In our analysis we refer to three such methods, which can be recast as educated inflation of the p-values, which is equivalent to raising the bar required to reject the null. The result of these procedures is an adjusted p-value.

Table 3 includes two adjustment methods (columns 9 and 10), the widely used false discovery rate (FDR) of Benjamini and Hochberg, ${ }^{94}$ and the less powerful but more conservative Bonferroni-Holm method..$^{95}$ In the discussion of Table 2 we refer to the Bonferroni method, which is the most conservative. While Bonferroni-Holm is more powerful, the Bonferroni method boils down to a single inflated threshold which made it the simplest and most intuitive in the context of that discussion.

\footnotetext{
${ }^{94}$ Yoav Benjamini and Yosef Hochberg, "Controlling the False Discovery Rate: A Practical and Powerful Approach to Multiple Testing," Journal of the Royal Statistical Society. Series B, Statistical Methodology 57.1 (1995), 289-300.

${ }^{95}$ Sture Holm, "A Simple Sequentially Rejective Multiple Test Procedure," Scandinavian Journal of Statistics, Theory and Applications 6.2 (1979), 65-70.
}

Cite this article: De Weerdt H, Ho B, Wagner A, Qiao J, Chu M (2020). Is There a Faction in This List?. Journal of Chinese History 4, 347-389. https://doi.org/10.1017/jch.2020.16 